\title{
Comparative study of flow separation control using suction and blowing over an airfoil with/without flap
}

\author{
ESMAEEL FATAHIAN ${ }^{1}$, ALI LOHRASBI NICHKOOHI ${ }^{2, *}$, HESAMODDIN SALARIAN $^{1}$ and \\ JAHANFAR KHALEGHINIA ${ }^{1}$
}

${ }^{1}$ Department of Mechanical Engineering, Nour Branch, Islamic Azad University, Nour, Iran

${ }^{2}$ Department of Mechanical Engineering, Nowshahr Branch, Islamic Azad University, Nowshahr, Iran

e-mail: lohrasbi@iauns.ac.ir

MS received 8 February 2019; revised 22 July 2019; accepted 13 August 2019; published online 11 October 2019

\begin{abstract}
This study mainly focused on the comparison of the effect of single and simultaneous suction and blowing jets on the aerodynamic performance of an airfoil with/without flap to evaluate the most effective flow control configuration using computational fluid dynamics (CFD) method. Moreover, the effect of applying single and simultaneous jets have been conducted on delaying and controlling the flow separation. The results were obtained using two-dimensional incompressible Unsteady Reynolds-Averaged Navier-Stokes (URANS), and the turbulence was simulated with SST k- $\omega$ turbulence model. Also, different parameters including two jet locations $\left(\mathrm{L}_{\text {jet }}\right)$, three jet velocity ratios $\left(\mathrm{R}_{\text {jet }}\right)$, three jet angles $\left(\theta_{\text {jet }}\right)$ and three flap deflections $\left(\delta_{\mathrm{f}}\right)$ were analyzed to find the most effective case of applying flow control jets to delay the boundary layer separation. It was concluded that applying a single suction jet and simultaneous suction and blowing jets on the flapped airfoil was more effective to improve the lift-to-drag ratio $\left(\mathrm{C}_{\mathrm{L}} / \mathrm{C}_{\mathrm{D}}\right)$ than applying these jets to the without flap case. The maximum value of $C_{L} / C_{D}$ was achieved by single suction jet for the without flap case which was equal to 73.7. The maximum increment of stall angle over the without flap airfoil and flapped airfoil was obtained by applying single suction jet, which increased the stall angle from $14^{\circ}$ to $20^{\circ}$ and $14^{\circ}$ to $16^{\circ}$ for the suction angle of $-90^{\circ}$ and suction velocity ratio of 0.15 , respectively.
\end{abstract}

Keywords. Flow separation; suction; blowing; lift coefficient; drag coefficient; flapped airfoil.

\section{Introduction}

In the domain of aerospace and aviation, the existence of flow separation leads to the instability of flying vehicles, the generation of noise, increasing drag and decreasing lift. The flow separation control technology has been gradually developed as an important branch of mechanics [1-3]. Researchers in aerodynamic have done massive work for controlling flow separation to increase the aerodynamic performance of flying vehicles. All the proposed methods can be divided into the active and passive flow control methods, according to the criterion whether or not external energy is required [4]. No auxiliary power and no control loop is required for passive flow separation and energy expenditure is required for active flow separation control [5]. Control of flow separation can be conducted using active methods such as a small energy input by suction and blowing jets [6-8], synthetic jet actuators (SJA) [2] and plasma-based flow control methods [9], or passive methods such as changing the airfoil geometry, adding high-lift

*For correspondence devices such as trailing-edge flaps and leading-edge slats, vortex generators, dimples and Gurney flaps [10-12]. Many experimental and numerical studies have been done to control the flow separation and both active and passive methods have been suggested to attain separation control. Shehata et al [13] studied experimentally the effects of a movable trailing-edge flap for NACA 0012 airfoil, actuation start time, and flap deflection angles on the critical aerodynamic values. Their results indicated good agreement with Leishman's model at a lower amplitude and frequency of oscillations, but larger discrepancies at higher amplitudes and frequency of oscillations were observed. Mohammadi and Taleghani [14] experimentally investigated the impact of the plasma actuator over NACA 0012 airfoil at high angles of attack up to $6^{\circ}$ above the stall in order to displace the separation point. Their results showed that the lift coefficient raised with unsteady plasma actuation at post-stall angles of attack up to $6^{\circ}$. In the study of Arunraj et al [15], an attempt was made to increase the lift coefficient using suction at various points and delaying boundary layer separation. Their experimental results suggested that the suction is highly effective at low suction 
pressures. Periodic excitation by oscillatory blowing for use in separation control has been documented extensively by Seifert et al [16-18] and in the review by Greenblatt and Wygnanski [19]. James et al [20] numerically studied a secondary blowing slot over NACA 0012 airfoil and LA203A high lift airfoil. The simulation conducted with a blowing ratio of 0 (no blowing) and compared with the experimental results done by Critzos et al [21]. Their results demonstrated that the secondary blowing helps to control flow separation and cause an increment in the lift and delay the stalling of airfoils in both cases. Genc et al [22] numerically investigated blowing and suction methods on the NACA 2415 airfoil in transient area. Separation bubbles did not completely disappear in blowing and suction simulation, but either reduced in number or moved downstream. Their study showed that the best results can be achieved with suction only. Yousefi et al [23] studied the effects of jet width on blowing and suction flow control for the NACA 0012 airfoil. Tangential and perpendicular blowing and perpendicular suction were applied on the airfoil upper surface. They found that the lift-to-drag ratio improved when the suction jet width increased. Boualem et al [24] analyzed the efficiency of the synthetic jet as an active control device to improve the aerodynamic performance of the NACA 0015 airfoil. Their results demonstrated that the use of synthetic jet increased the lift coefficient by about $13.3 \%$ and decreased the drag coefficient about $52.7 \%$. Lei et al [25] investigated a suction control of the laminar separation bubble over the NACA 2415 airfoil at low Reynolds number at different angles of attack. Their results showed that suction control can decrease the velocity gradient of the boundary layer, delay the transition and prevent generating the separation bubble. Tadjfar and Asgari [26] investigated the influence of a tangential blowing jet in the dynamic stall of the NACA 0012 airfoil. They concluded that placing the jet slot within a very small range upstream of the counter-clockwise (CCW) vortex had tremendous effects on both lift and drag coefficients. Obeid et al [27] investigated a 2D subsonic flow over the NACA 0015 airfoil with a $30 \%$ trailing edge flap for a range of flap deflections and various angles of attack. Their numerical results revealed that the increasing of flap deflections enhance the maximum lift coefficient and decrease the stall angle. Numerical investigation of the aerodynamic performance of the NACA 0015 airfoil with an integral-type trailing edge flap was conducted by Hassan [28] using the 2D ARC2D Navier-Stokes flow solver developed at the NASA-ARC. Zhou et al [4] numerically considered the effects of Mach number on the flow separation control of an airfoil with a small plate near the leading edge. They created a mutual interference between the trailing vortex generated using the small plate and the boundary layer of the airfoil for flow separation control. They concluded that better aerodynamic performance of the airfoil achieved in this way. Zhang et al [29] numerically analyzed the suction control for flow separation of the
NACA 0012 airfoil. The suppression effects of suction were studied considering many parameters such as angle, suction coefficient, hole, location, width, and porosity. The variations in energy consumption and lift-drag ratio during the control process were used to evaluate the control effects. Ma et al [30] numerically and experimentally investigated the effects of suction flow control on the aerodynamic force of the wing at low Reynolds numbers. They concluded that when the suction holes are close to the separation point, the suction has the best control effect.

The present study was performed to compare the ability of flow control jets on improving the aerodynamic performance of an airfoil with/without flap. Computational fluid dynamics (CFD) method was conducted to investigate the effect of applying a single jet and simultaneous suction and blowing jets for controlling the flow separation over an airfoil with/without flap. For this purpose, the blowing and suction control jets were computationally studied using different control parameters including jet location $\left(\mathrm{L}_{\mathrm{jet}}\right)$, jet velocity ratio $\left(R_{\text {jet }}\right)$ and jet angle $\left(\theta_{\text {jet }}\right)$. Also, different flap deflections were used to have a better understanding of the effect of applying control jets on controlling the boundary layer over the flapped airfoil.

\section{Governing equations and turbulence model}

The fluid flow was modeled as a two-dimensional, unsteady, turbulent, and viscous incompressible flow. The incompressible Unsteady Reynolds-Averaged NavierStokes (URANS) equations consisting of the continuity equation, which represents the conservation of mass, and the momentum equation, representing the conservation of momentum which can be written as follows [31]:

$$
\begin{gathered}
\frac{\partial}{\partial x_{i}}\left(u_{i}\right)=0 \\
\rho \frac{\partial}{\partial t}\left(u_{i}\right)+\rho \frac{\partial}{\partial x_{j}}\left(u_{i} u_{j}\right)= \\
-\frac{\partial P}{\partial x_{i}}+\mu \frac{\partial}{\partial x_{j}}\left(\frac{\partial u_{i}}{\partial x_{j}}\right) \\
+\frac{\partial}{\partial x_{j}}\left(-\rho\left\langle u_{j}^{\prime} u_{i}^{\prime}\right\rangle\right)
\end{gathered}
$$

where $u_{i}$ is the ensemble averaged velocity in the i-direction, and symbols $\rho, \mu$, and P correspond to the density, molecular viscosity, and ensemble averaged pressures, respectively. The single term in the continuity equation represents the mass advection, while the first and second terms on the left-hand side in the momentum equation are the transient and momentum advection terms. The three terms on the right-hand side of the momentum equation are the pressure force, viscous term, and the Reynolds stress. The Reynolds stress term $-\rho\left\langle u_{j}^{\prime} u_{i}^{\prime}\right\rangle$ in Eq. (2) contains the mean of the product of turbulent fluctuating velocities modeled by the Boussinesq approximation. This term requires turbulence model to close the system of equations. 


$$
-\rho\left\langle u_{j}^{\prime} u_{i}^{\prime}\right\rangle=\mu_{t}\left(\frac{\partial u_{i}}{\partial x_{j}}+\frac{\partial u_{j}}{\partial x_{i}}\right)-\frac{2}{3} \rho k \delta_{i j}
$$

where $\mu_{\mathrm{t}}$ and $\mathrm{k}$ represent the turbulent viscosity and turbulent kinetic energy. $\delta_{i j}$ is Kronecker Delta.

In the present study, the Unsteady Reynolds-Averaged Navier-Stokes equations were solved with the shear stress transport (SST) k- $\omega$ turbulence model [32] adopted to simulate the boundary layer turbulence. SST k- $\omega$ turbulence model provides excellent predictive capability for flows with separation [32-35] as mentioned in previous studies of similar flows [23, 26, 36]. This model includes both $\mathrm{k}-\omega$ and $\mathrm{k}-\varepsilon$ standard models, which improves the calculations of boundary layer flows with separation and removes the sensitivity of the $\mathrm{k}-\omega$ model for external flows. SST k- $\omega$ turbulence model consists of turbulent kinetic energy transport equation and turbulent kinetic energy dissipation rate transport equation [37] which can be written as follows [32]:

$$
\begin{gathered}
\frac{\partial}{\partial t}(\rho k)+\frac{\partial}{\partial x_{i}}\left(\rho k u_{i}\right)=\frac{\partial}{\partial x_{j}}\left[\Gamma_{k} \frac{\partial k}{\partial x_{j}}\right]+G_{k}-Y_{k} \\
\frac{\partial}{\partial t}(\rho \omega)+\frac{\partial}{\partial x_{i}}\left(\rho \omega u_{i}\right)=\frac{\partial}{\partial x_{j}}\left[\Gamma_{\omega} \frac{\partial \omega}{\partial x_{j}}\right]+G_{\omega}-Y_{\omega}+D_{\omega}
\end{gathered}
$$

where $\Gamma_{k}$ and $\Gamma_{\omega}$ represent the effective diffusivity of $k$ and $\omega$, respectively. $G_{k}$ and $G_{\omega}$ indicate the generation of $k$ and $\omega$ due to mean velocity gradients, respectively. $Y_{k}$ and $Y_{\omega}$ are the dissipation of $\mathrm{k}$ and $\omega$, respectively. $\mathrm{D}_{\omega}$ denotes the cross-diffusion term of $\omega$. The dissipation and the generation terms are defined as follows: [37, 38]:

$$
\begin{gathered}
Y_{k}=\rho \beta^{*} k \omega \\
Y_{\omega}=\rho \beta \omega^{2} \\
G_{k}=\mu_{t} S^{2}
\end{gathered}
$$

$$
G_{\omega}=\frac{\alpha}{v_{t}} G_{k}
$$

where turbulent viscosity $\mu_{\mathrm{t}}$ is obtained from the combination of $\mathrm{k}$ and $\omega$ according to the following equation:

$$
\begin{gathered}
\mu_{t}=\frac{\rho k}{\omega} \frac{1}{\max \left[\frac{1}{\alpha^{*}}, \frac{S F_{2}}{\alpha_{1} \omega}\right]} \\
\beta^{*}=\beta_{i}^{*}\left[1+\zeta^{*} F\left(M_{t}\right)\right] \\
\beta=\beta_{i}\left[1-\frac{\beta_{i}^{*}}{\beta_{i}} \zeta^{*} F\left(M_{t}\right)\right]
\end{gathered}
$$

\section{Computational grid and boundary conditions}

In the present study, the computational grid was meshed with a C-type structured grid which is shown in figure 1a. The computational domain was extended from 6 chords upstream to 12 chords downstream and upper and lower boundaries were extended 6 chords from the profile with a 1 $\mathrm{m}$ airfoil chord length, large enough to prevent the outer boundary from affecting the near flow field around the airfoil [7]. On the airfoil surface, no-slip wall condition was applied. The velocity inlet boundary condition was imposed at the inlet, upper and lower boundaries, with a uniform velocity $U_{\infty}=7.3 \mathrm{~m} / \mathrm{s}$ corresponding to a chord Reynolds number of $5 \times 10^{5}$ and a turbulent intensity of $0.1 \%$, while the pressure outlet $\left(\mathrm{P}=\mathrm{P}_{\infty}\right)$ boundary condition was used at the outlet (figure $1 \mathrm{~b}$ ). In addition, velocity inlet boundary condition was imposed at the jets location. Figure 2 illustrates closer views of the grid around the NACA 0012 airfoil and the NACA 0012 flapped airfoil with different flap deflections. Moreover, a C-type structured grid of the NACA 0012 airfoil with flow control jets is illustrated in figure 3.
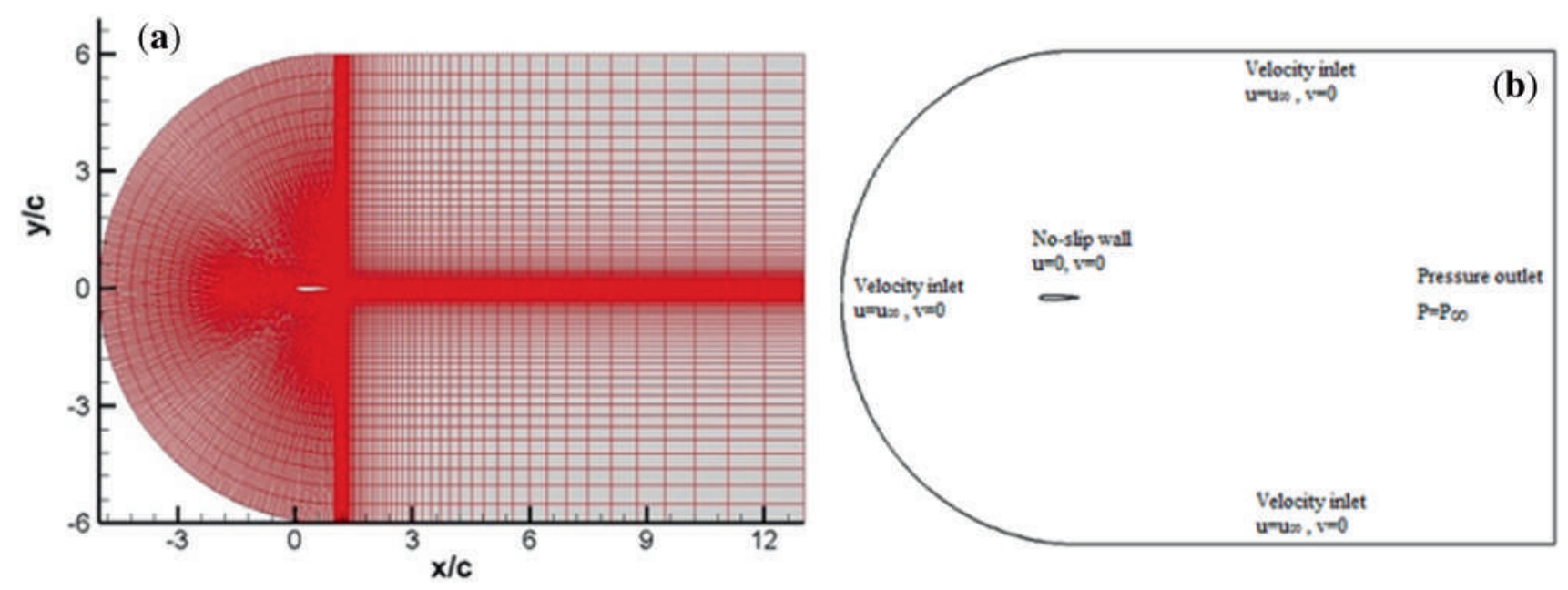

Figure 1. The schematic view of (a) a C-type structured grid of NACA 0012 airfoil and (b) boundary condition. 

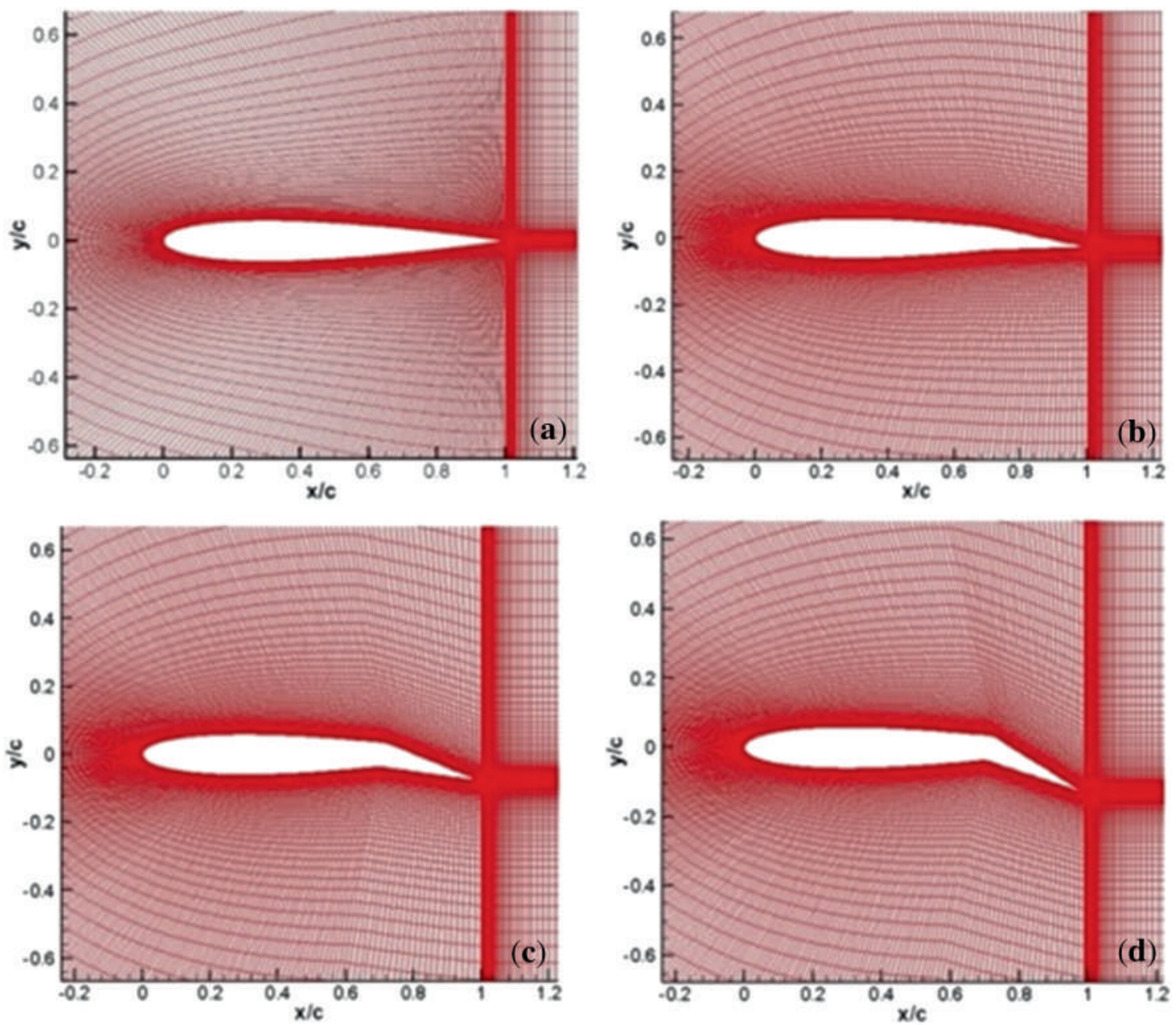

Figure 2. Closer views of the grid around (a) NACA 0012 airfoil, (b) flap deflection of $5^{\circ}$, (c) flap deflection of $15^{\circ}$ and (d) flap deflection of $30^{\circ}$.

\section{Grid independence study}

In most researches, lift coefficient $\left(\mathrm{C}_{\mathrm{L}}\right)$, drag coefficient $\left(C_{D}\right)$ and the lift-to-drag ratio $\left(C_{L} / C_{D}\right)$ are usually adopted for measuring the aerodynamic performance, which can be written as follows:

$$
\begin{gathered}
C_{L}=\frac{L}{\frac{1}{2} \rho_{a} U_{\infty}^{2} c} \\
C_{D}=\frac{D}{\frac{1}{2} \rho_{a} U_{\infty}^{2} c} \\
\frac{L}{D}=\frac{C_{L}}{C_{D}}
\end{gathered}
$$

where $\mathrm{L}$ is the lift, $\mathrm{D}$ is the drag, a and $\mathrm{U}_{\infty}$ are air density and free stream velocity, $\mathrm{c}$ is the airfoil chord length [39, 40].

Grid independence study was carried out for different cells by considering $C_{L}$ and $C_{D}$ as parameters. Four
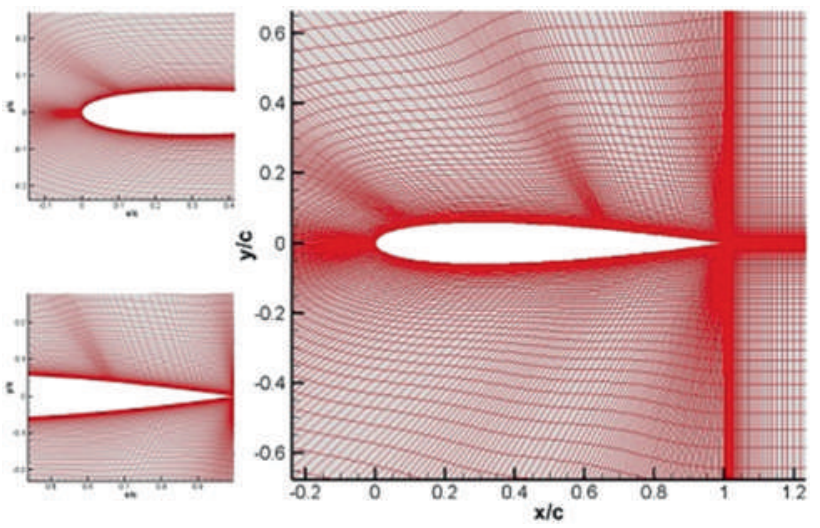

Figure 3. A C-type structured grid of NACA 0012 airfoil with flow control jets.

different grids with cell numbers of 19000, 34000, 52000 and 74000 were generated for grid independence study. In order to calculate lift and drag coefficients, the angles of attack of $10^{\circ}$ and $16^{\circ}$ with a chord Reynolds number of 
Table 1. Grid independence study for the NACA 0012 airfoil at $\alpha=10^{\circ}$ and $\alpha=16^{\circ}$.

\begin{tabular}{cccccc}
\hline & \multicolumn{2}{c}{$\alpha=10^{\circ}$} & & \multicolumn{2}{c}{$\alpha=16^{\circ}$} \\
\cline { 2 - 3 } \cline { 5 - 6 } $\begin{array}{l}\text { Number of } \\
\text { cells }\end{array}$ & $\begin{array}{c}\text { Lift } \\
\text { coefficient }\end{array}$ & $\begin{array}{c}\text { Drag } \\
\text { coefficient }\end{array}$ & & $\begin{array}{c}\text { Lift } \\
\text { coefficient }\end{array}$ & $\begin{array}{c}\text { Drag } \\
\text { coefficient }\end{array}$ \\
\hline 19000 & 1.091 & 0.0362 & & 1.016 & 0.1252 \\
34000 & 1.022 & 0.0279 & & 0.982 & 0.1106 \\
52000 & 0.981 & 0.0232 & & 0.974 & 0.0928 \\
74000 & 0.979 & 0.0231 & & 0.972 & 0.0926 \\
\hline
\end{tabular}

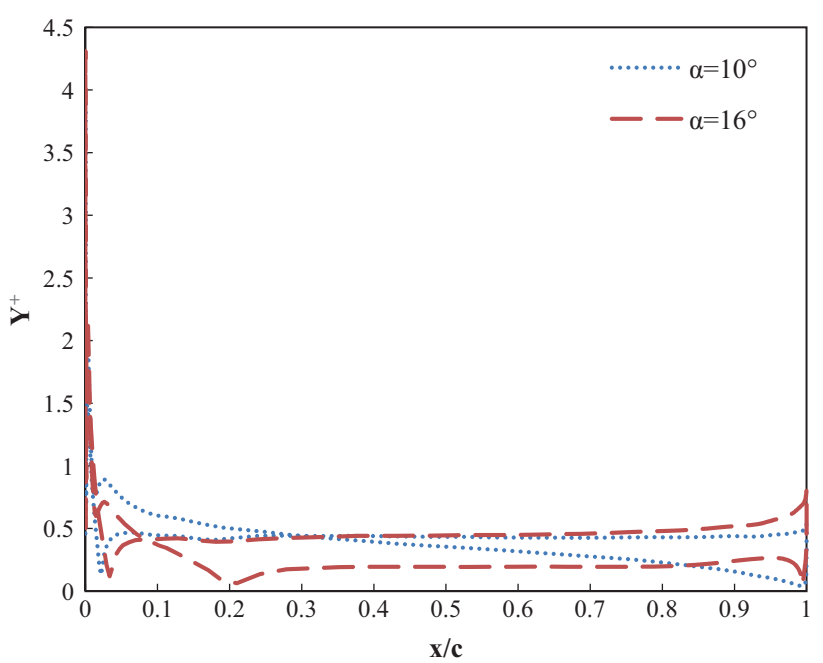

Figure 4. $\mathrm{Y}^{+}$distribution over the NACA 0012 airfoil without control case at $\alpha=10^{\circ}$ and $\alpha=16^{\circ}$.

$5 \times 10^{5}$ were selected as shown in table 1 . There was a negligible difference between the results of the smallest grid and the grid with 52000 cells. The grid size giving a grid independent result with reasonable accuracy was selected to be 52000 nodes. Versteeg and Malalasekera [41] reported that the value of $\mathrm{Y}^{+}$should be $\sim 1$ and the near wall mesh resolution was determined by this value. The wall $\mathrm{Y}^{+}$values for NACA 0012 airfoil without control case at two angels of attack $\left(\alpha=10^{\circ}\right.$ and $\left.\alpha=16^{\circ}\right)$ are presented in figure 4. In addition, $\mathrm{Y}^{+}$distributions over NACA 0012 airfoil with a single suction jet and a single blowing jet at $\alpha$ $=16^{\circ}$ are illustrated in figure 5. In our study, the wall $\mathrm{Y}^{+}$ value was ensured to be less than 1 for all cases.

Table 2 indicates some details of four different grids including number of cells and $\mathrm{Y}^{+}$distribution. The C-type structured grid captures the leading edge curvature without any singularities. In order to predict the separation zone more accurately, dense grid resolutions were adopted in the near field of leading edge and trailing edge of the airfoil to tackle with the issues of high skewness and singularity at trailing edge. 240 computational nodes were employed on the airfoil suction side and 210 nodes on the pressure side. The distance of nearest node from trailing edge and leading edge was $0.0001 \mathrm{~m}$ and $0.001 \mathrm{~m}$, respectively. Also, the distance of

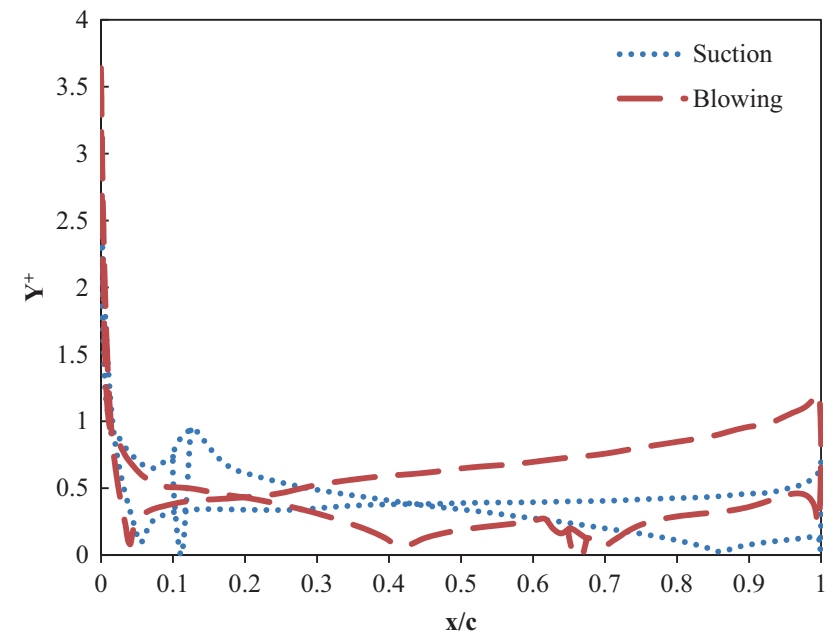

Figure 5. $\mathrm{Y}^{+}$distribution over the NACA 0012 airfoil with a single suction jet and a single blowing jet at $\alpha=16^{\circ}$.

nearest node from the airfoil surface was $1 \times 10^{-5} \mathrm{~m}$ which ensured that the near-wall $\mathrm{Y}^{+}$values to be less than 1 . Besides, the growth rate for the size of the grid in the normal direction of the airfoil surface was ensured to be less than 1.1.

\section{Numerical method}

In this study, all present simulations were performed with the pressure-based finite volume solver of the commercial software ANSYS Fluent 18.2. Calculations were carried out over the NACA 0012 airfoil with $1 \mathrm{~m}$ chord length and a chord Reynolds number of $5 \times 10^{5}$. A low free-stream turbulence level was used to match the wind tunnel characteristics, so the stream turbulence intensity was selected as less than $0.1 \%$. In addition, SIMPLE coupled algorithm [23, 26, 42, 43] was applied for pressure-velocity coupling and upwind second-order method was employed to discretize the governing equations. A sufficiently time step of $1 \times 10^{-4}$ were used to achieve Courant-Friedrichs-Lewy (CFL) number lower than 1 and the results converged when the scaled residual is less than $1 \times 10^{-6}$.

\section{Modeling of suction and blowing}

In this study, the blowing and suction control jets were computationally studied using different control parameters. Figure 6 illustrates the NACA 0012 airfoil geometry, jet location $\left(\mathrm{L}_{\mathrm{jet}}\right)$, jet velocity ratio $\left(\mathrm{R}_{\mathrm{jet}}\right)$ and jet angle $\left(\theta_{\mathrm{jet}}\right)$. Here, $\theta_{\text {jet }}$ is the angle between the local jet surface and jet entrance velocity direction. It should be noted that a negative $\theta$ indicates the suction condition and positive $\theta$ represents blowing condition. The jet location $\left(\mathrm{L}_{\mathrm{jet}}\right)$ for applying suction was located at $10 \%$ of the chord length from the leading edge because of previous studies recommendations 
Table 2. Details of the grid cells and $\mathrm{Y}^{+}$distribution at $\alpha=10^{\circ}$ and $\operatorname{Re}=5 \times 10^{5}$.

\begin{tabular}{ccccrrr}
\hline Grid & Number of cells & Growth factor & The height of the first cell $(\mathrm{m})$ & Max $\mathrm{Y}^{+}$ & ${\text {Min } \mathrm{Y}^{+}}^{\text {Average } \mathrm{Y}^{+}}$ \\
\hline 1 & 19000 & 1.1 & $3 \times 10^{-3}$ & 22.13 & 7.72 & 10.14 \\
2 & 34000 & 1.1 & $1 \times 10^{-4}$ & 9.11 & 3.32 \\
3 & 52000 & 1.1 & $1 \times 10^{-5}$ & 3.93 & 0.04 & 0.89 \\
4 & 74000 & 1.1 & $5 \times 10^{-6}$ & 3.86 & 0.03 & 0.81 \\
\hline
\end{tabular}

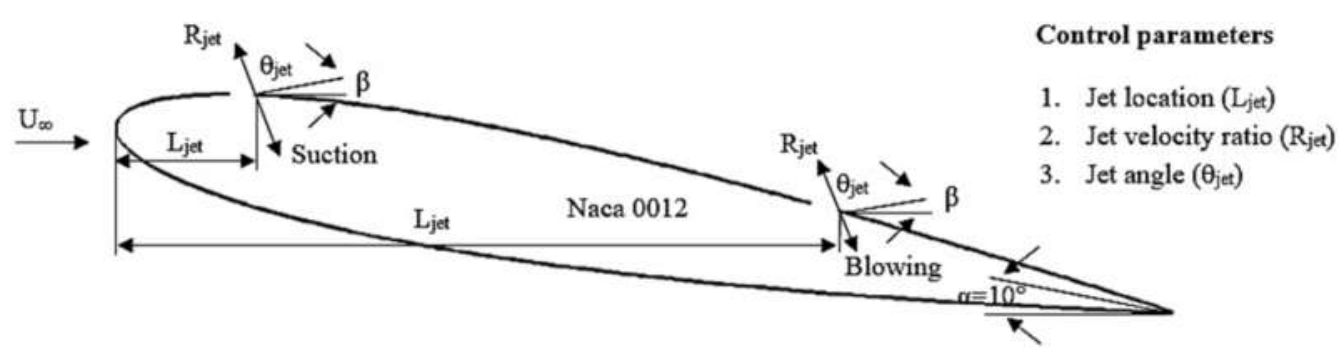

Figure 6. Definitions of the control jets parameters.

$[2,7,44]$. Generally, the blowing in the trailing edge has significant effect on decreasing the drag force [45]. Also, by locating the blowing slot nearer to the flow separation location, it has more impact on delaying flow separation. For this reason, a blowing jet was placed at $\mathrm{L}_{\text {jet }}=0.65$.

In order to apply suction and blowing jets, velocity inlet was considered as a boundary condition. The jet entrance velocity is defined as [22]:

$$
\begin{gathered}
R_{\text {jet }}=\frac{U_{\text {jet }}}{U_{\infty}} \\
u=U_{\text {jet }} \cos \left(\theta_{\text {jet }}+\beta\right) \\
v=U_{\text {jet }} \sin \left(\theta_{\text {jet }}+\beta\right)
\end{gathered}
$$

where $U_{\infty}$ is the free stream velocity which is equal to $7.3 \mathrm{~m} / \mathrm{s}$, $\mathrm{U}_{\text {jet }}$ is jet velocity, and $\beta$ is the angle between the freestream velocity direction and normal to the local jet surface. Firstly, a jet with a width of $2.5 \%$ of the chord length was placed on the airfoil upper surface to simulate the blowing/suction jet. The jet width for single suction and single blowing was fixed at $2.5 \%$ chord length which is stated by Dannenberg and Weiberg [46]. They indicated that an increase of suction area beyond $2.5 \%$ chord length will not significantly increase lift. Secondly, the effects of simultaneous blowing and suction were investigated over NACA 0012 airfoil. Tables 3, 4 and 5 indicate the configurations of blowing/suction jet, simultaneous jets and flap deflections over NACA 0012 airfoil as well as the values of control parameters.

\section{Validation}

In the present study, computational results of lift and drag coefficients were compared with the available experimental results of Critzos et al [21], Jacobs et al [47], and numerical
Table 3. Configurations of single jets.

\begin{tabular}{llll}
\hline Case & $\mathrm{L}_{\text {jet }}$ & $\mathrm{R}_{\text {jet }}$ & \multicolumn{1}{c}{$\theta_{\text {jet }}$} \\
\hline Suction & 0.1 & 0.05 & $-30^{\circ},-60^{\circ},-90^{\circ}$ \\
Suction & 0.1 & 0.1 & $-30^{\circ},-60^{\circ},-90^{\circ}$ \\
Suction & 0.1 & 0.15 & $-30^{\circ},-60^{\circ},-90^{\circ}$ \\
Blowing & 0.65 & 0.05 & $30^{\circ}, 60^{\circ}, 90^{\circ}$ \\
Blowing & 0.65 & 0.1 & $30^{\circ}, 60^{\circ}, 90^{\circ}$ \\
Blowing & 0.65 & 0.15 & $30^{\circ}, 60^{\circ}, 90^{\circ}$ \\
\hline
\end{tabular}

Table 4. Configurations of simultaneous jets.

\begin{tabular}{lllll}
\hline Case & \multicolumn{1}{c}{ Jet } & $\mathrm{L}_{\text {jet }}$ & $\mathrm{R}_{\text {jet }}$ & \multicolumn{1}{c}{$\theta_{\text {jet }}$} \\
\hline Simultaneous & Suction & 0.1 & 0.05 & $-30^{\circ},-60^{\circ},-90^{\circ}$ \\
suction and blowing & Blowing & 0.65 & 0.05 & $30^{\circ}, 60^{\circ}, 90^{\circ}$ \\
Simultaneous & Suction & 0.1 & 0.1 & $-30^{\circ},-60^{\circ},-90^{\circ}$ \\
suction and blowing & Blowing & 0.65 & 0.1 & $30^{\circ}, 60^{\circ}, 90^{\circ}$ \\
Simultaneous & Suction & 0.1 & 0.15 & $-30^{\circ},-60^{\circ},-90^{\circ}$ \\
suction and blowing & Blowing & 0.65 & 0.15 & $30^{\circ}, 60^{\circ}, 90^{\circ}$ \\
\hline
\end{tabular}

Table 5. Configurations of flap deflections.

\begin{tabular}{lc}
\hline Case & Flap deflection $\left(\delta_{\mathrm{f}}\right)$ \\
\hline The flapped airfoil & $5^{\circ}$ \\
& $15^{\circ}$ \\
& $30^{\circ}$ \\
\hline
\end{tabular}

results of Huang et al [7] and Yousefi et al [23] all at Re = $5 \times 10^{5}$ which is provided in figure 7 . Good agreement was obtained between computational results and mentioned studies. Also, the pressure coefficient $\left(\mathrm{C}_{\mathrm{p}}\right)$ was compared with the numerical results of Huang et al [7], Farhadi et al [48] and experimental results of Gregory and O'reilly [49] for $\operatorname{Re}=5 \times 10^{5}$ and $\alpha=18^{\circ}$, as shown in figure 8 . As it can 


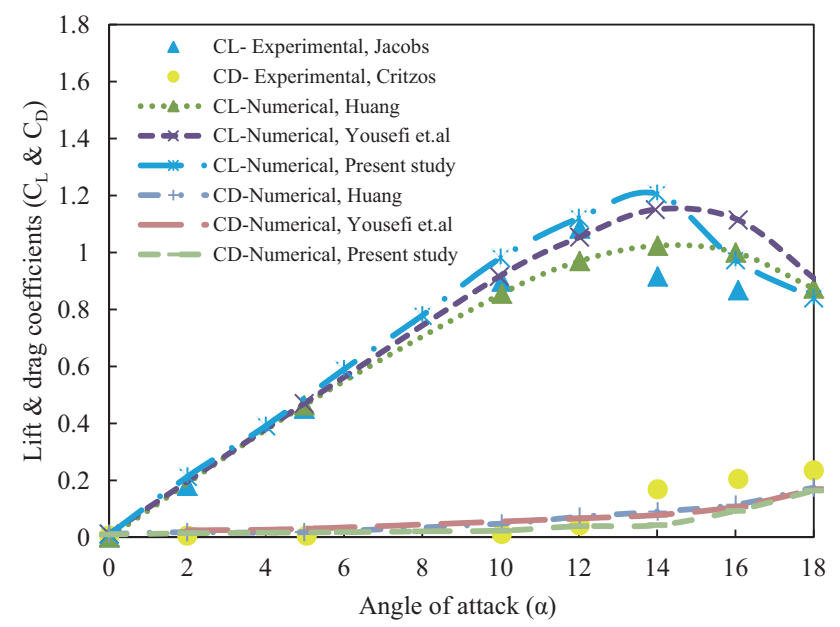

Figure 7. Comparison between the lift and drag coefficients with experimental results of Critzos et al [21], Jacobs et al [47] and numerical results of Huang et al [7] and Yousefi et al [23].

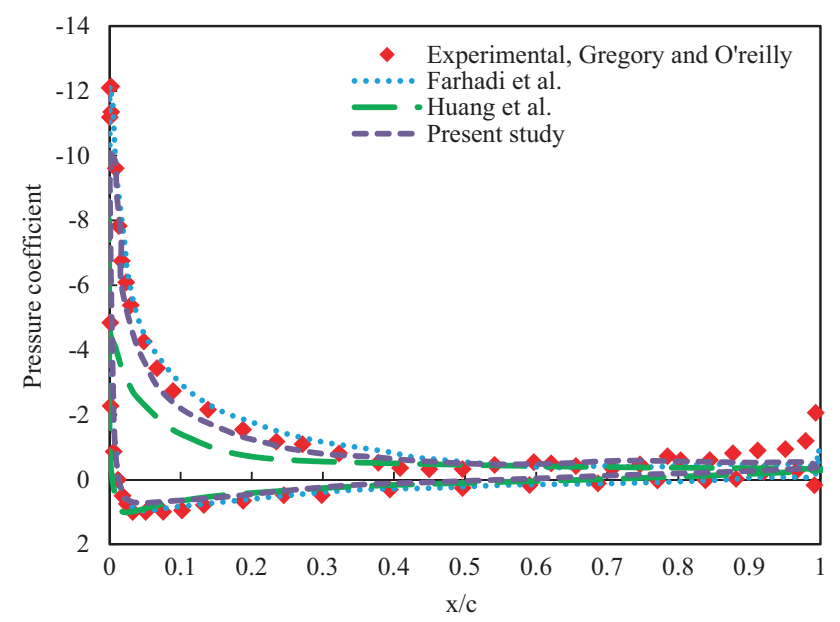

Figure 8. Comparison between the pressure coefficient (Cp) with the numerical results of Huang et al [7], Farhadi et al [48] and experimental results of Gregory and O'reilly [49].

be seen, our numerical results have good agreement with the mentioned numerical and experimental results. Therefore, it can be said that the numerical solving procedure and the applied turbulent model has acceptable accuracy.

In table 6, due to the lack of experimental results on suction and blowing flow control over a NACA 0012 airfoil at the present flow conditions, the computational results of $\mathrm{C}_{\mathrm{L}} / \mathrm{C}_{\mathrm{L}-\mathrm{Base}}$ ratio were compared with the numerical results of Huang et al [7] under a Reynolds number of $5 \times 10^{5}$, the angle of attack of $18^{\circ}$ and a suction/blowing jet width of $2.5 \%$ of the chord length. For single suction and single blowing cases, jet locations were placed at 0.1 and 0.65 from the leading edge of the airfoil, respectively. As it can be seen, the numerical results have excellent agreement with the numerical results of Huang et al [7].

\section{Results and discussions}

\subsection{Changes of lift and drag coefficients based on jet angles}

Figures 9 and 10 demonstrate the effect of jet angles on the lift and drag coefficients for three cases including single suction, single blowing, and simultaneous suction and blowing. In these figures, three jet angles of $30^{\circ}, 60^{\circ}$, and $90^{\circ}$ compared to the without control cases over NACA 0012 airfoil. In the case of suction, a small amount of air is sucked from the main flow. The low energy fluid in the boundary layer is removed by suction before it can separate and eliminates its losses [50]. By locating the suction slot nearer to the leading edge, it has more impact on flow separation control. As mentioned before in suction case, the jet location $\left(\mathrm{L}_{\mathrm{jet}}\right)$ was located at $10 \%$ of the chord length from the leading edge due to the previous recommendations $[2,7,44]$. Hence, for single suction case, a suction jet was placed at $\mathrm{L}_{\text {jet }}=0.1$ with $\mathrm{R}_{\text {jet }}=0.15$. By increasing the suction angle, the value of the lift coefficient increased and the drag coefficient decreased. These changes were negligible for angles of attack lower than $10^{\circ}$ which is also stated by Yousefi et al [23]. The lift coefficient enhanced by $41 \%$, and the drag coefficient reduced by $78 \%$, with a suction velocity ratio of 0.15 and a jet angle of $-90^{\circ}$ at $\alpha=$ $16^{\circ}$. Furthermore, increasing the suction jet angle led to improve the stall angle. The stall angle increased from $14^{\circ}$ to $16^{\circ}, 14^{\circ}$ to $18^{\circ}$ and $14^{\circ}$ to $20^{\circ}$ for suction angles of $-30^{\circ}$ to $-90^{\circ}$, respectively.

Generally, the blowing in the trailing edge has significant effect on decreasing the drag force [45]. The blowing method has been used for suppressing separation by increasing the momentum of the boundary layer. It has been effective in adjusting and re-energizing the flow for suppressing flow separation. By importing momentum to the boundary layer, blowing prevents the boundary layer thickening and separation, consequently, decrease drag coefficient [51]. Hence, by locating the blowing slot nearer

Table 6. Comparison of $\mathrm{C}_{\mathrm{L}} / \mathrm{C}_{\mathrm{L}-\mathrm{Base}}$ ratio with the numerical results of Huang et al [7].

\begin{tabular}{lcccc}
\hline Case study & $\begin{array}{c}\text { Blowing }\left(\theta_{\text {jet }}=30^{\circ}\right) \\
\mathrm{C}_{\mathrm{L}} / \mathrm{C}_{\mathrm{L} \text {-base }}\end{array}$ & $\begin{array}{c}\text { Blowing }\left(\theta_{\text {jet }}=90^{\circ}\right) \\
\mathrm{C}_{\mathrm{L}} / \mathrm{C}_{\mathrm{L} \text {-base }}\end{array}$ & $\begin{array}{c}\text { Suction }\left(\theta_{\text {jet }}=-30^{\circ}\right) \\
\mathrm{C}_{\mathrm{L}} / \mathrm{C}_{\mathrm{L}-\text { base }}\end{array}$ & $\begin{array}{c}\text { Suction }\left(\theta_{\text {jet }}=-90^{\circ}\right) \\
\mathrm{C}_{\mathrm{L}} / \mathrm{C}_{\mathrm{L}-\text { base }}\end{array}$ \\
\hline Huang et al $[7]$ & 1.212 & 0.881 & 1.342 & 1.502 \\
Present study & 1.207 & 0.877 & 1.338 & 1.497 \\
\hline
\end{tabular}



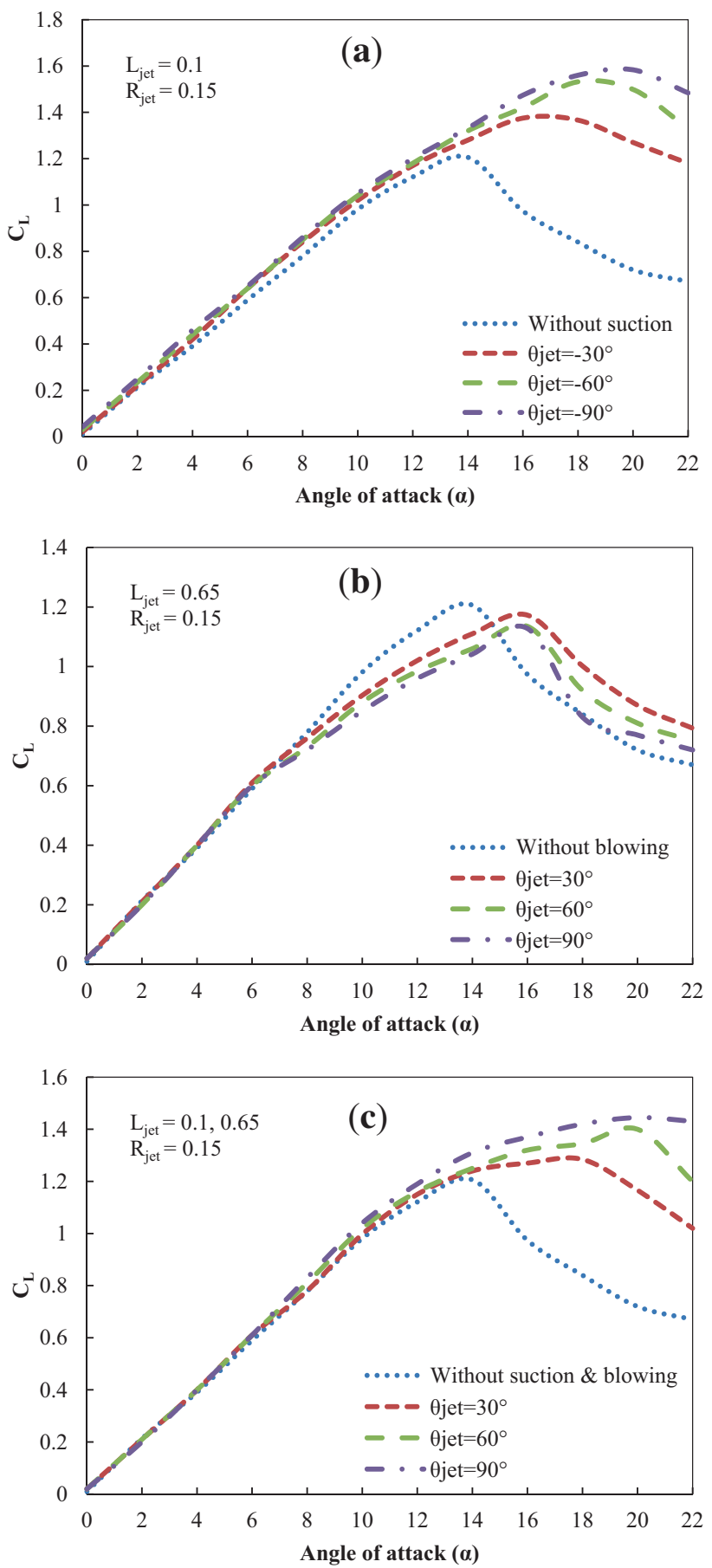

Figure 9. The effect of jet angles on the lift coefficient for (a) single suction, (b) single blowing and (c) simultaneous suction and blowing.

to the flow separation location, it has more impact on delaying flow separation. For this reason, a blowing jet was placed at $\mathrm{L}_{\text {jet }}=0.65$ with $\mathrm{R}_{\text {jet }}=0.15$ for single blowing case. In this case, small jet angles had more effect on the improvement of stall angle contrary to the single suction case. The lift coefficient increased by $20 \%$ and the drag coefficient decreased by $39 \%$ with $\mathrm{R}_{\mathrm{jet}}=0.15$ and a jet
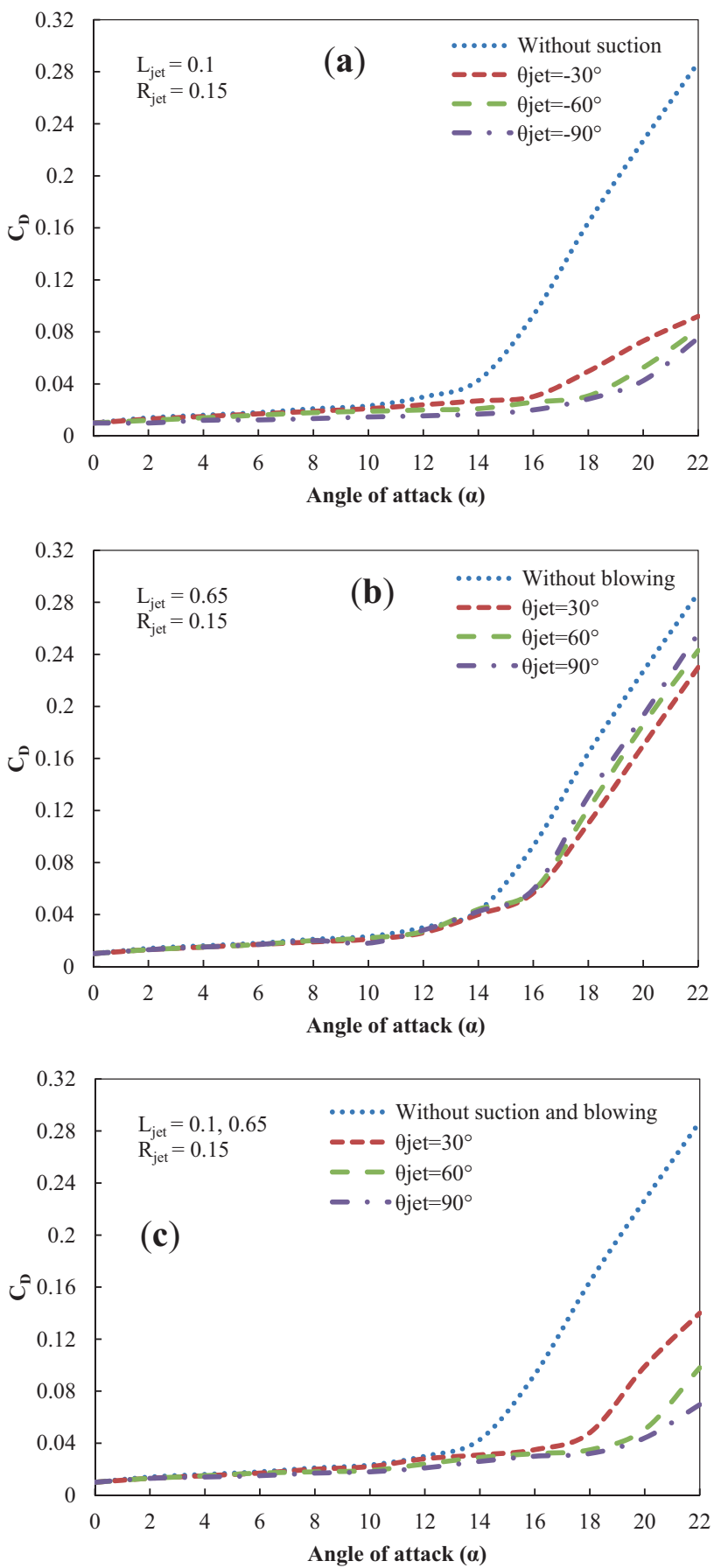

Figure 10. The effect of jet angles on drag coefficient for (a) single suction, (b) single blowing and (c) simultaneous suction and blowing.

angle of $+30^{\circ}$ at $\alpha=16^{\circ}$. In the case of simultaneous suction and blowing, a suction jet was placed at $\mathrm{L}_{\text {jet }}=0.1$ with $\mathrm{R}_{\text {jet }}=0.15$ and a blowing jet was placed at $\mathrm{L}_{\text {jet }}=0.65$ with $R_{\text {jet }}=0.15$. The stall angle increased from $14^{\circ}$ to $18^{\circ}$, $14^{\circ}$ to $20^{\circ}$ and $14^{\circ}$ to $20^{\circ}$ for jet angles of $\pm 30^{\circ}$ to $\pm 90^{\circ}$, respectively. The lift coefficient enhanced by $39 \%$ and the drag coefficient reduced by $67 \%$ with a jet velocity ratio of 
0.15 and jet angles of $\pm 90^{\circ}$ at $\alpha=16^{\circ}$. Consequently, the best results obtained with single suction and simultaneous suction and blowing cases, respectively. The worst results obtained with a single blowing case. Suction and blowing have been shown to provide lift augmentation (and drag reduction) in the presence of adverse pressure gradients by suppressing or at least retarding flow separation as well as increasing the stall angle $[52,53]$.

\subsection{Changes of lift and drag coefficients based on jet velocity ratios}

Figures 11 and 12 show the effect of jet velocity ratios on the lift and drag coefficients for three cases including single suction, single blowing, and simultaneous suction and blowing. In these figures, three jet velocity ratios of 0.05 , 0.1 and 0.15 compared to the without control cases over NACA 0012 airfoil. For single suction case, a suction jet was placed at $\mathrm{L}_{\text {jet }}=0.1$ with $\theta_{\text {jet }}=-90^{\circ}$. By increasing the suction velocity ratio, the value of the lift coefficient increased and the drag coefficient reduced. The lift coefficient enhanced by $31 \%, 43 \%$ and $51 \%$ at $\alpha=16^{\circ}$ for suction velocity ratios of $0.05,0.1$ and 0.15 , respectively. On the contrary, the drag coefficient decreased by $57 \%$, $68 \%$ and $78 \%$ at $\alpha=16^{\circ}$ for suction velocity ratios of 0.05 , 0.1 and 0.15 , respectively. From this result, it was concluded that the velocity ratio of 0.15 had the most effect on aerodynamics coefficients and improvement of stall angle. For single blowing case, a suction jet was placed at $\mathrm{L}_{\text {jet }}=$ 0.65 with $\theta_{\text {jet }}=+30^{\circ}$. The lift coefficient increased by $27 \%$, $24 \%$ and $20 \%$ at $\alpha=16^{\circ}$ for suction velocity ratios of 0.05 , 0.1 and 0.15 , respectively. Also, the drag coefficient decreased by $41 \%, 39 \%$ and $36 \%$ at $\alpha=16^{\circ}$ for blowing velocity ratios of $0.05,0.1$ and 0.15 , respectively. It is obvious that changes in blowing velocity ratio had no considerable effect on the aerodynamic coefficients of the airfoil. But smaller blowing velocity ratio $\left(R_{\text {jet }}=0.05\right)$ had the most effect on increasing the lift coefficient and decreasing drag coefficient. When the blowing velocity ratio increased, stall showed no alteration and occured at the same angle of attack of $14^{\circ}$ [23]. For simultaneous suction and blowing case, a suction jet was placed at $\mathrm{L}_{\mathrm{jet}}=$ 0.1 with $\theta_{\text {jet }}=-90^{\circ}$ and a blowing jet was placed at $\mathrm{L}_{\text {jet }}=$ 0.65 with $\theta_{\text {jet }}=+30^{\circ}$. The lift coefficient improved by $25 \%, 33 \%$ and $41 \%$ at $\alpha=16^{\circ}$ for suction velocity ratios of $0.05,0.1$ and 0.15 , respectively. Also, the drag coefficient decreased by $57 \%, 65 \%$ and $67 \%$ at $\alpha=16^{\circ}$ for blowing velocity ratios of $0.05,0.1$ and 0.15 , respectively.

\subsection{Changes of the lift-to-drag ratio $\left(C_{L} / C_{D}\right)$ based on jet angles}

Figure 13 depicts the effect of jet angles on the lift-to-drag ratio $\left(C_{L} / C_{D}\right)$ for three cases including single suction,
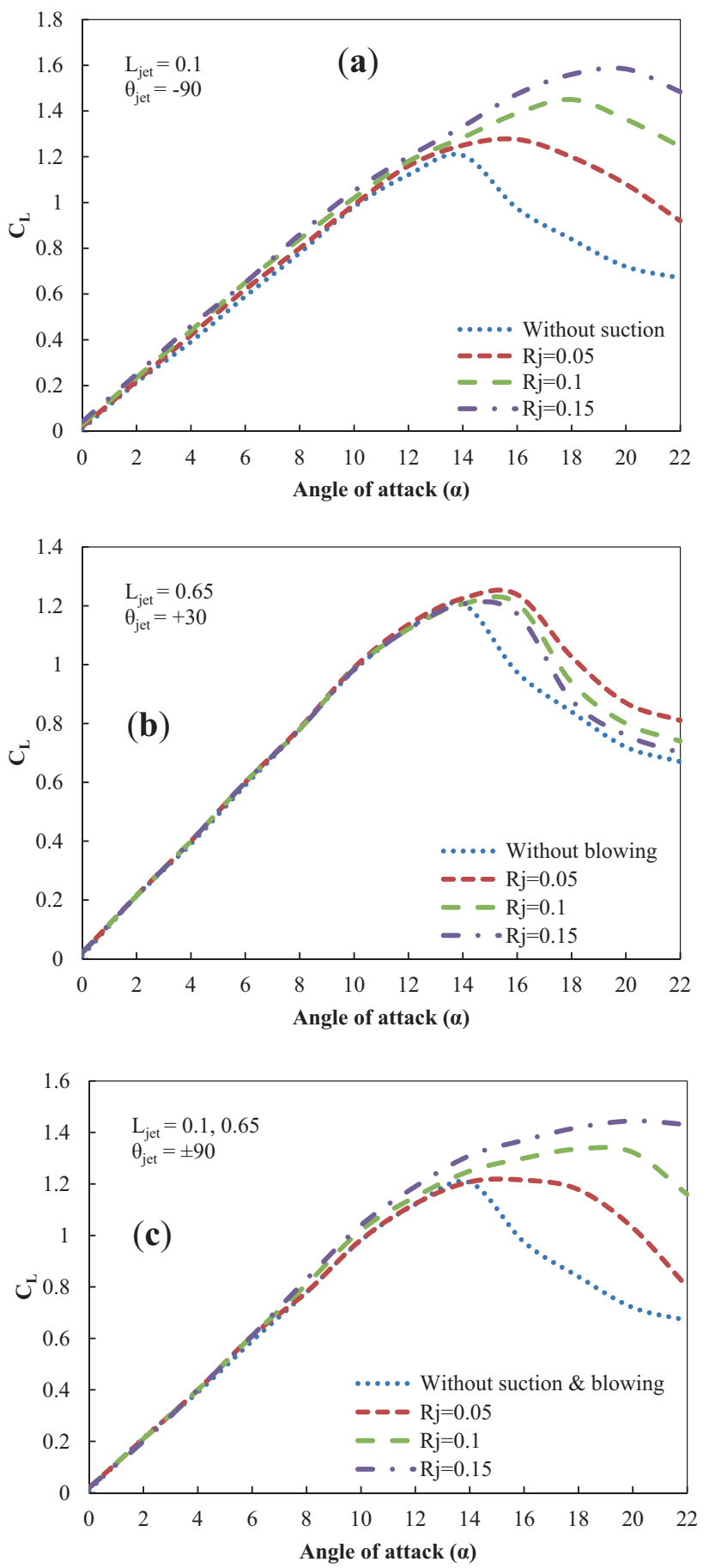

Figure 11. The effect of jet velocity ratios on the lift coefficient for (a) single suction, (b) single blowing and (c) simultaneous suction and blowing.

single blowing, and simultaneous suction and blowing. In this figure, three jet angles of $30^{\circ}, 60^{\circ}$ and $90^{\circ}$ and $\mathrm{R}_{\text {jet }}=$ 0.15 compared to the without control cases over NACA 0012 airfoil. Unlike for single blowing case, both single suction and simultaneous suction and blowing cases had positive effects on aerodynamic performance. It should be noted that applying single suction with a jet angle of $-90^{\circ}$ 

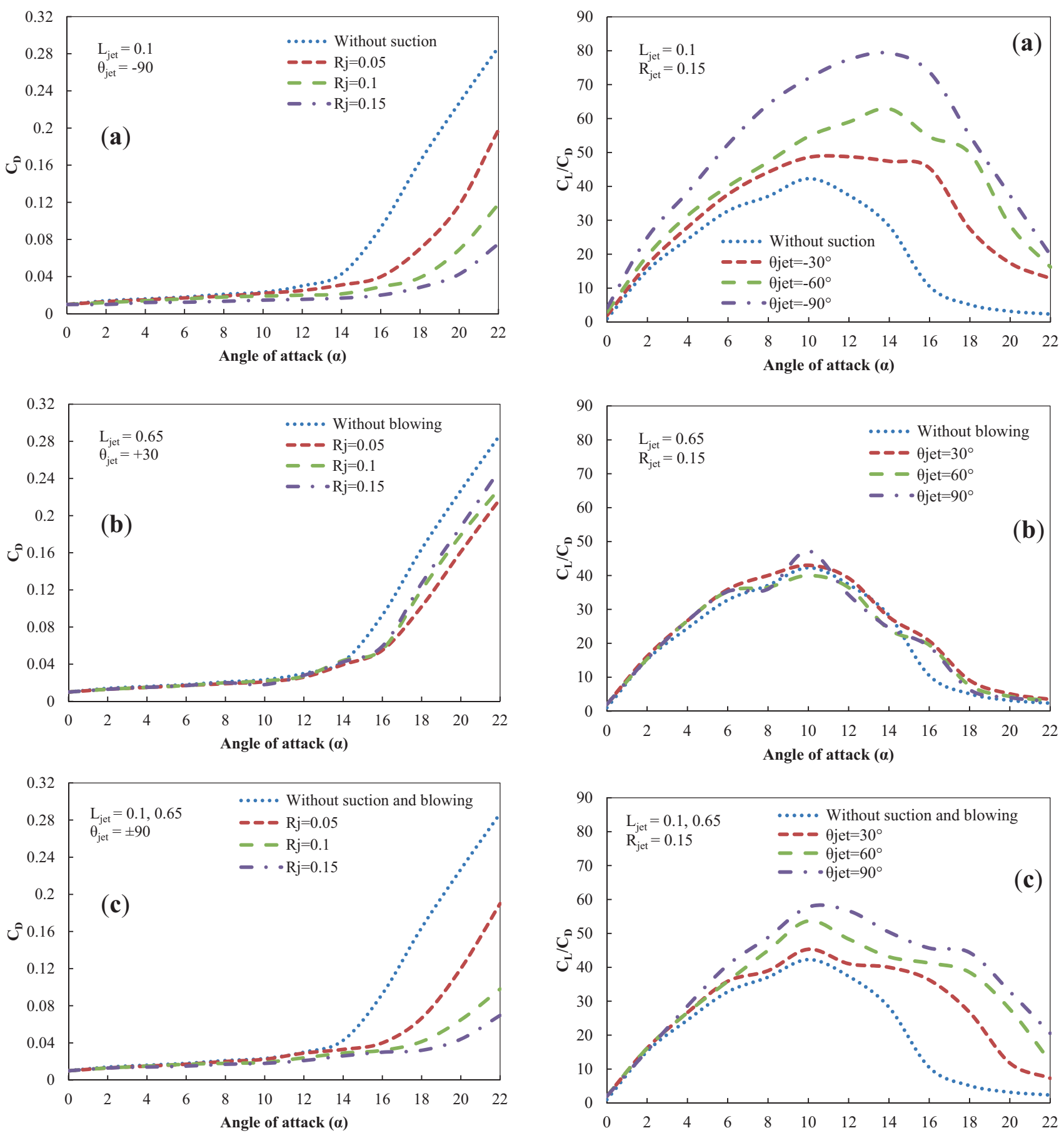

Figure 12. The effect of jet velocity ratios on drag coefficient for (a) single suction, (b) single blowing and (c) simultaneous suction and blowing.

had the most effect on increasing the lift-to-drag ratio compared to the other cases which increased from 10.5 to 73.7 at $\alpha=16^{\circ}$. The reason for the changes in the lift-todrag ratio was due to the applying suction and blowing jets. Applying these jets with appropriate conditions caused to increase the velocity and decrease the pressure over the upper surface of the airfoil resulting in enhancing lift force.

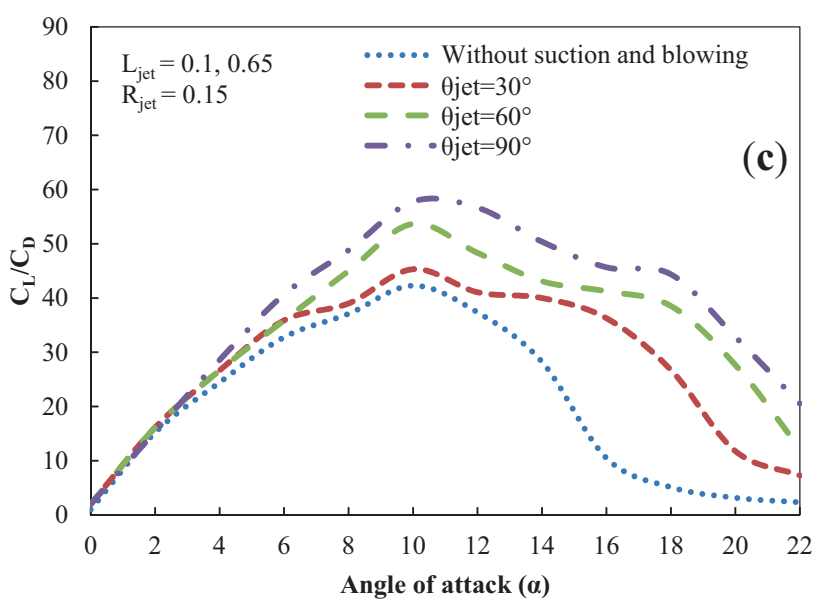

Figure 13. The effect of jet angles on the lift-to-drag ratio for (a) single suction, (b) single blowing and (c) simultaneous suction and blowing.

\subsection{The effect of flap deflections $\left(\delta_{f}\right)$ on the aerodynamic performance}

Figures 14 and 15 illustrate the effect of flap deflections $\left(\delta_{\mathrm{f}}\right)$ on the lift and drag coefficients for three cases. In these figures, three flap deflections of $5^{\circ}, 15^{\circ}$, and $30^{\circ}$ compared to the without flap case. It is obvious that the lift coefficient 


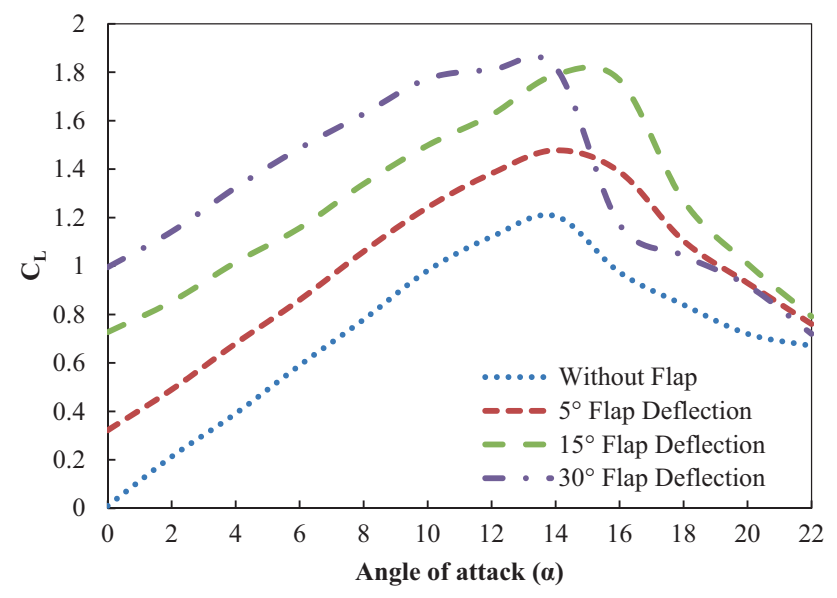

Figure 14. The effect of flap deflections on the lift coefficient.

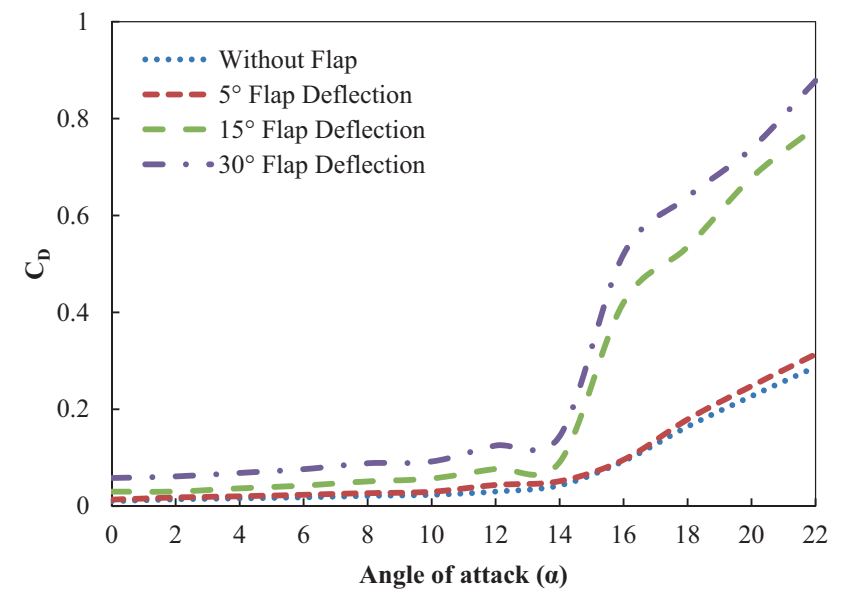

Figure 15. The effect of flap deflections on the drag coefficient.

enhanced dramatically by increasing flap deflections. The maximum increment of the value of lift coefficient was about $51 \%$ more than the without flap case which obtained by flap deflections of $30^{\circ}$ at $\alpha=14^{\circ}$. One other interesting observation is about the prediction of the stall angle. Using the flap caused to enhance the value of lift coefficient but did not improve the stall angle. On the other hand, the drag coefficient increased with the increase of flap deflections so that the drag coefficient increased more than 5 times at $\alpha=$ $16^{\circ}$.

These results are undesirable for the aerodynamic point of view which are indicated in figure 16. Although, using the flap had a positive effect on the increment of the lift coefficient, but it had an unsuitable effect on drag coefficient which caused to reduce the lift-to-drag ratio especially at high flap deflections $\left(\delta_{\mathrm{f}}\right)$. In addition, a comparison of the effect of flap deflection on lift coefficient is shown in figure 17 for $\alpha=10^{\circ}$ with numerical results of Obeid et al [27] and experimental results of Williamson [54]. It is evident that the lift coefficient increases sharply with the increment of flap deflections [27].

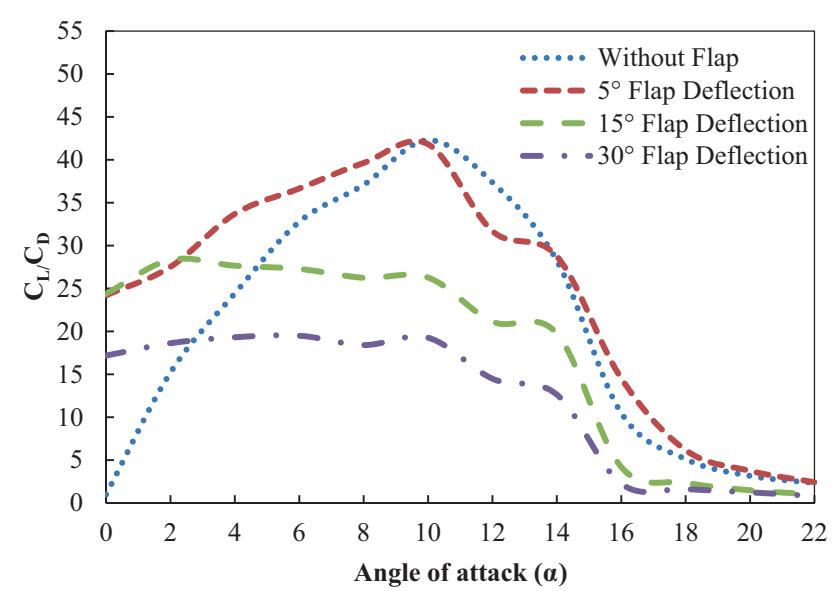

Figure 16. The effect of flap deflections on the lift-to-drag ratio.

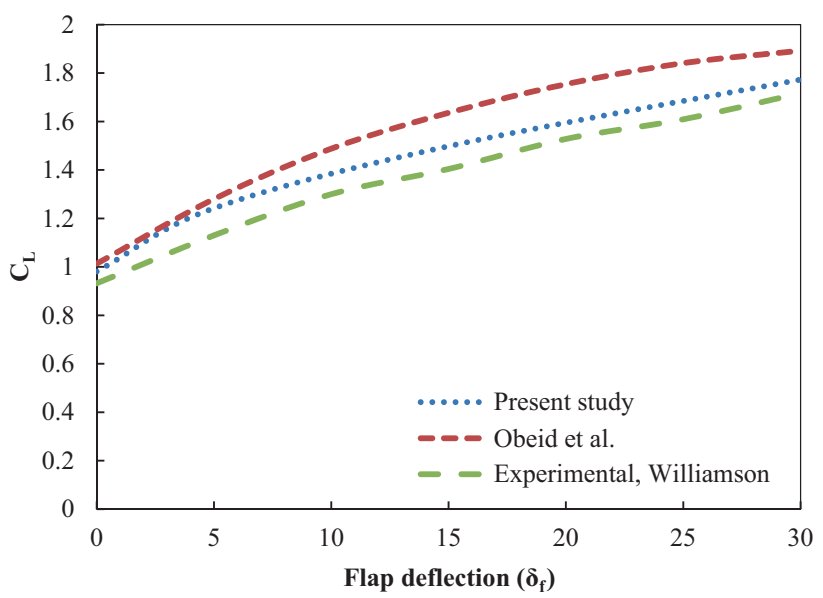

Figure 17. Comparison of the effect of flap deflection on lift coefficient for $\alpha=10^{\circ}$ with numerical results of Obeid et al [27] and experimental results of Williamson [54].

\subsection{Changes of lift and drag coefficients based on jets angles on the flapped airfoil}

Figures 18 and 19 show the effect of jet angles on the lift and drag coefficients of the flapped airfoil with a deflection of $30^{\circ}\left(\delta_{\mathrm{f}}=30^{\circ}\right)$ for three cases including single suction, single blowing, and simultaneous suction and blowing. In these figures, three jet angles of $30^{\circ}, 60^{\circ}$, and $90^{\circ}$ compared to the without control cases over NACA 0012 flapped airfoil with a deflection of $30^{\circ}$. As it can be seen, a single suction jet and simultaneous suction and blowing jets had more significant effect on improving the stall angle than a single blowing jet. For single suction case, a suction jet was placed at $\mathrm{L}_{\mathrm{jet}}=0.1$ with $\mathrm{R}_{\text {jet }}=0.15$. Increasing the suction angle led to improve the lift coefficient and reduce the drag coefficient. In this case, the lift coefficient enhanced about $60 \%$ and the drag coefficient decreased by $82 \%$ with $\mathrm{R}_{\text {jet }}=$ 0.15 and jet angle of $-90^{\circ}$ compared to the without control cases over NACA 0012 airfoil with deflection of $30^{\circ}$. A 

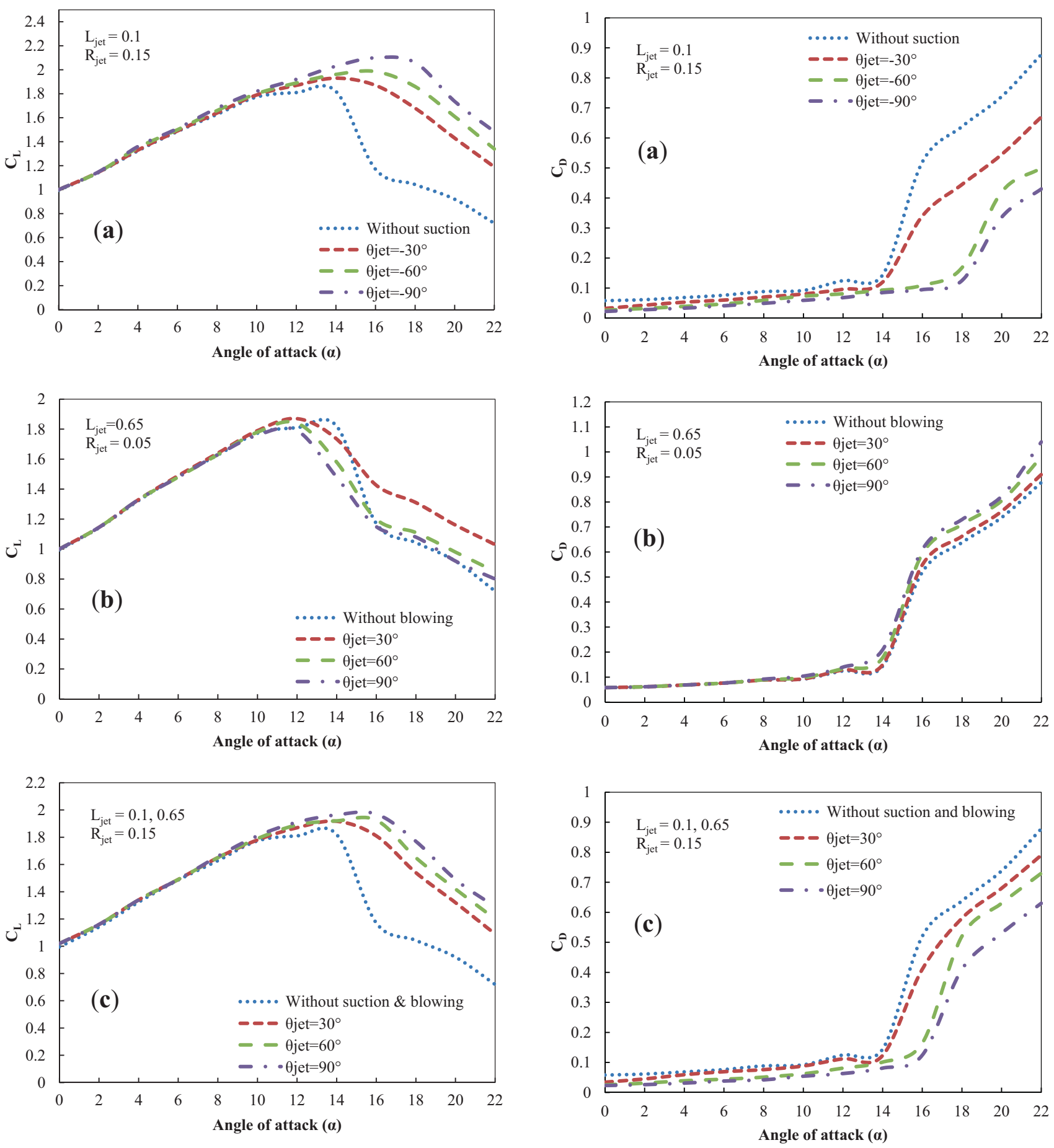

Figure 18. The effect of jet angles on the lift coefficient of the flapped airfoil for (a) single suction, (b) single blowing and (c) simultaneous suction and blowing.

blowing jet was placed at $L_{\text {jet }}=0.65$ with $R_{\text {jet }}=0.05$ for single blowing case. In this case, only the smallest blowing angle $\left(\theta_{\text {jet }}=30^{\circ}\right)$ improved the stall angle from $14^{\circ}$ to $16^{\circ}$. It is worth mentioning that applying single blowing on the flapped airfoil did not decrease the drag coefficient so that it caused to have a negative effect on the aerodynamic

Figure 19. The effect of jet angles on the drag coefficient of the flapped airfoil for (a) single suction, (b) single blowing and (c) simultaneous suction and blowing.

performance. In the case of simultaneous suction and blowing, a suction jet was placed at $\mathrm{L}_{\mathrm{jet}}=0.1$ with $\mathrm{R}_{\mathrm{jet}}=$ 0.15 and a blowing jet was placed at $\mathrm{L}_{\mathrm{jet}}=0.65$ with $\mathrm{R}_{\mathrm{jet}}=$ 0.05 . The lift coefficient increased by $68 \%$ and the drag coefficient reduced by $76 \%$ with $\mathrm{R}_{\text {jet }}=0.15$ and jet angles of $\pm 90^{\circ}$ at $\alpha=16^{\circ}$. 


\subsection{Changes of lift and drag coefficients based on jet velocity ratios on the flapped airfoil}

Figures 20 and 21 demonstrate the effect of jet velocity ratios on the lift and drag coefficients of the flapped airfoil with a deflection of $30^{\circ}\left(\delta_{\mathrm{f}}=30^{\circ}\right)$ for three cases including single suction, single blowing, and simultaneous suction
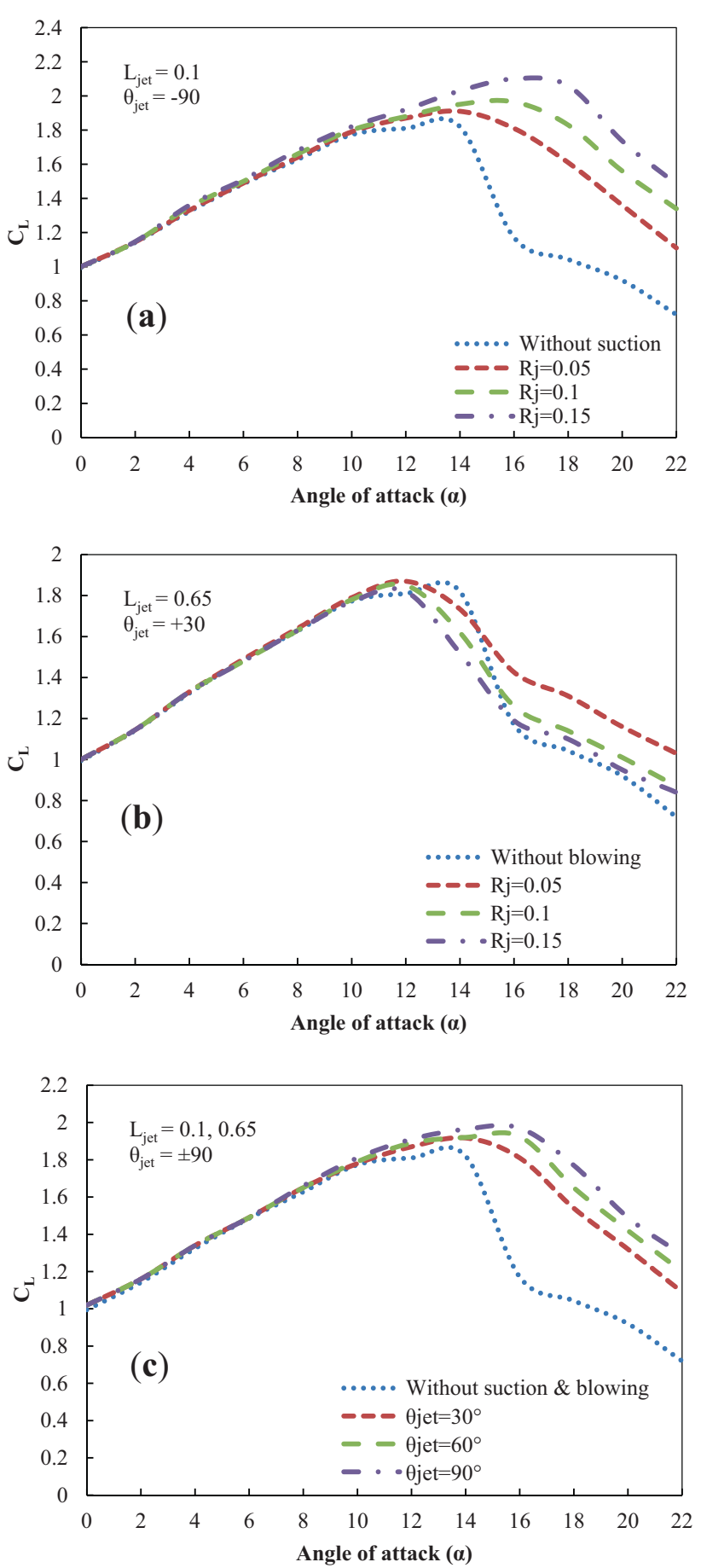

Figure 20. The effect of jet velocity ratios on the lift coefficient of the flapped airfoil for (a) single suction, (b) single blowing and (c) simultaneous suction and blowing. and blowing. In these figures, three jet velocity ratios of $0.05,0.1$ and 0.15 compared to the without control cases over NACA 0012 flapped airfoil with a deflection of $30^{\circ}$. The maximum increment of lift coefficient occurred in a suction velocity ratio of 0.15 and $\theta_{\text {jet }}=-90^{\circ}$, which increased approximately $79 \%$ at $\alpha=16^{\circ}$. In addition, the
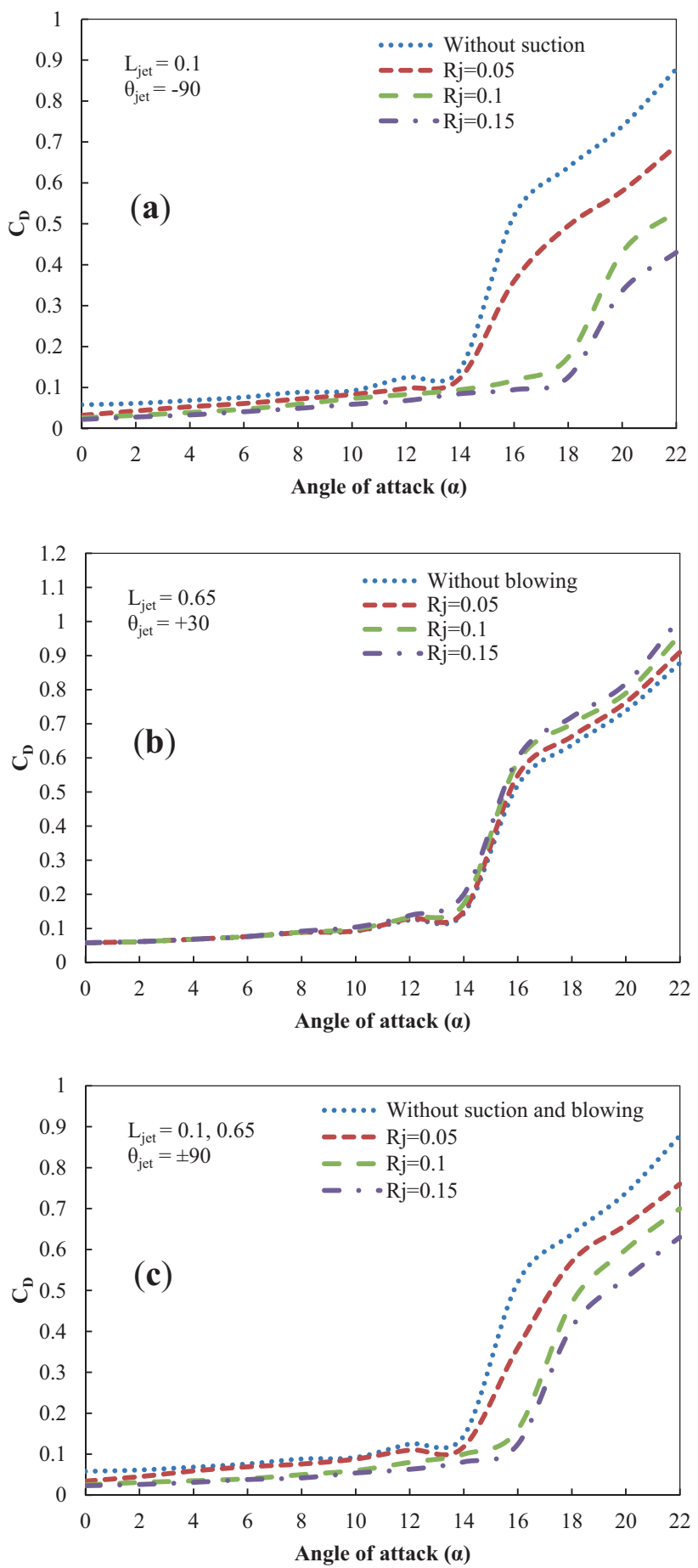

Figure 21. The effect of jet velocity ratios on the drag coefficient of the flapped airfoil for (a) single suction, (b) single blowing and (c) simultaneous suction and blowing. 
drag coefficient had a maximum reduction of about $81 \%$ at $\alpha=16^{\circ}$ with a suction velocity ratio of 0.15 and $\theta_{\text {jet }}=-90^{\circ}$. Applying single blowing did not affect the displacement of stall angle and had a negative effect on the drag coefficient. In all cases, the drag coefficient had increased which caused to reduce the aerodynamic performance. In the case of simultaneous suction and blowing, the lift coefficient improved by $68 \%$ and the drag coefficient decreased by $76 \%$ with $R_{\text {jet }}=0.15$ and jet angles of $\pm 90^{\circ}$ at $\alpha=16^{\circ}$.

\subsection{Changes of the lift-to-drag ratio $\left(C_{L} / C_{D}\right)$ based on jets angles on the flapped airfoil}

Figure 22 depicts the effect of jet angles on the lift-to-drag ratio of the flapped airfoil with a deflection of $30^{\circ}\left(\delta_{\mathrm{f}}=30^{\circ}\right)$ for three cases including single suction, single blowing, and simultaneous suction and blowing. In this figure, three jet angles of $30^{\circ}, 60^{\circ}$, and $90^{\circ}$ compared to the without control cases over NACA 0012 flapped airfoil with a deflection of $30^{\circ}$. It was found that applying blowing had a negligible effect on the aerodynamic performance of the flapped airfoil than other cases. Applying a single suction with a jet angle of $-90^{\circ}$ had the most effect on increasing the lift-todrag ratio among three cases.

\subsection{The most effective configurations jets for the airfoil with/without flap}

Table 7 shows the overall view of the comparison of most effective configurations of flow control jets including a single suction, a single blowing, and simultaneous suction and blowing for the airfoil with/without flap. In this table, the values of lift coefficient, drag coefficient and lift-todrag ratio are presented at an angle of attack of $16^{\circ}$. Although all findings of aerodynamic coefficients had compared in a wide range of angles of attack $(\alpha)$ between $0^{\circ}$ to $22^{\circ}$, a more detailed comparison was done at $\alpha=16^{\circ}$. In table 7 , the main reason for choosing this angle of attack was that a deep stall occurred at $\alpha=16^{\circ}$. Besides, the most positive effect of flow control methods on the aerodynamic performance of airfoil with/without flap was observed at $\alpha$ $=16^{\circ}$ for all cases. As mentioned before, for a single suction case, higher suction angles and suction velocity ratios had the most effect on aerodynamic coefficients. On the contrary, for a single blowing case, lower blowing angles and blowing velocity ratios had better results. Moreover, in the case of simultaneous suction and blowing, the values of the jet angles were chosen such that the best results were obtained for applying suction and blowing jets at these values. For this reason, a suction jet was placed at $\mathrm{L}_{\mathrm{jet}}=0.1$ with $R_{\text {jet }}=0.15$ and $\theta_{\text {jet }}=-90^{\circ}$ and a blowing jet was placed at $\mathrm{L}_{\mathrm{jet}}=0.65$ with $\mathrm{R}_{\mathrm{jet}}=0.05$ and $\theta_{\text {jet }}=+30^{\circ}$. Overall, the best results obtained with a single suction case, intermediate results obtained with simultaneous suction and
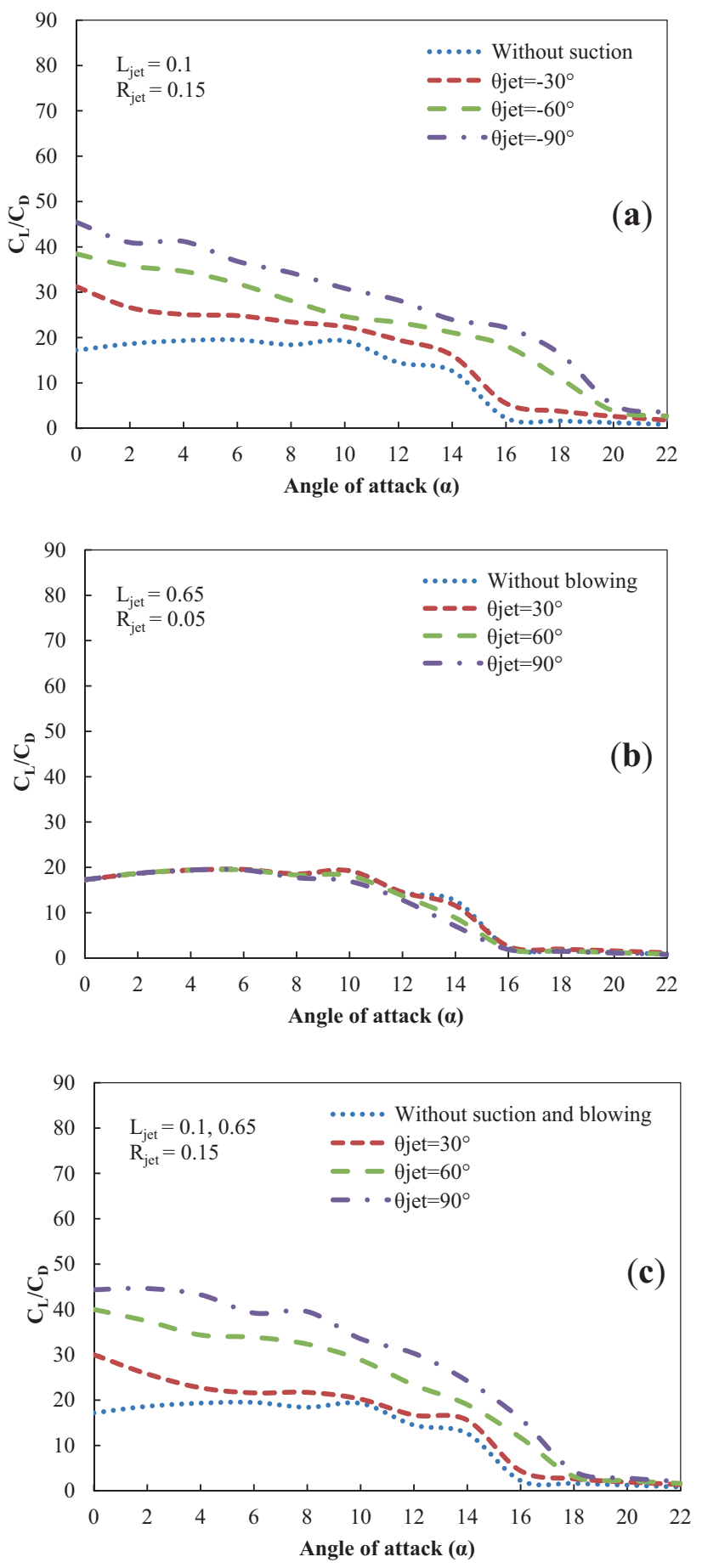

Figure 22. The effect of jets angles on the lift-to-drag ratio of the flapped airfoil for (a) single suction, (b) single blowing and (c) simultaneous suction and blowing.

blowing case and the worst results obtained with a single blowing case for the airfoil with/without flap. In a single suction case and simultaneous suction and blowing case, the value of the lift-to-drag ratio was obtained approximately 7 and 6 times greater than the without control cases over NACA 0012 airfoil, respectively. The maximum value of $C_{L} / C_{D}$ was achieved by a single suction jet for without 
Table 7. The comparison of the best results for the airfoil with/without flap.

\begin{tabular}{|c|c|c|c|c|c|c|c|c|}
\hline Case & Jet & $\mathrm{L}_{\text {jet }}$ & $\mathrm{R}_{\mathrm{jet}}$ & $\theta_{\text {jet }}$ & $\delta_{\mathrm{f}}$ & $\mathrm{C}_{\mathrm{L}}$ & $C_{D}$ & $\mathrm{C}_{\mathrm{L}} / \mathrm{C}_{\mathrm{D}}$ \\
\hline Without flap case & - & - & - & - & - & 0.974 & 0.093 & 10.47 \\
\hline Suction on without flap case & Suction & 0.1 & 0.15 & $-90^{\circ}$ & - & 1.474 & 0.020 & 73.70 \\
\hline Blowing on without flap case & Blowing & 0.65 & 0.05 & $30^{\circ}$ & - & 1.238 & 0.055 & 22.50 \\
\hline \multirow[t]{2}{*}{ Simultaneous suction and blowing on without flap case } & Suction & 0.1 & 0.15 & $-90^{\circ}$ & - & 1.363 & 0.022 & 61.95 \\
\hline & Blowing & 0.65 & 0.05 & $30^{\circ}$ & - & & & \\
\hline Flapped airfoil & - & - & - & - & $30^{\circ}$ & 1.171 & 0.520 & 2.25 \\
\hline Suction on flapped airfoil & Suction & 0.1 & 0.15 & $-90^{\circ}$ & $30^{\circ}$ & 2.1 & 0.095 & 22.11 \\
\hline Blowing on flapped airfoil & Blowing & 0.65 & 0.05 & $30^{\circ}$ & $30^{\circ}$ & 1.426 & 0.549 & 2.59 \\
\hline \multirow[t]{2}{*}{ Simultaneous suction and blowing on flapped airfoil } & Suction & 0.1 & 0.15 & $-90^{\circ}$ & $30^{\circ}$ & 2.016 & 0.101 & 19.96 \\
\hline & Blowing & 0.65 & 0.05 & $30^{\circ}$ & $30^{\circ}$ & & & \\
\hline
\end{tabular}
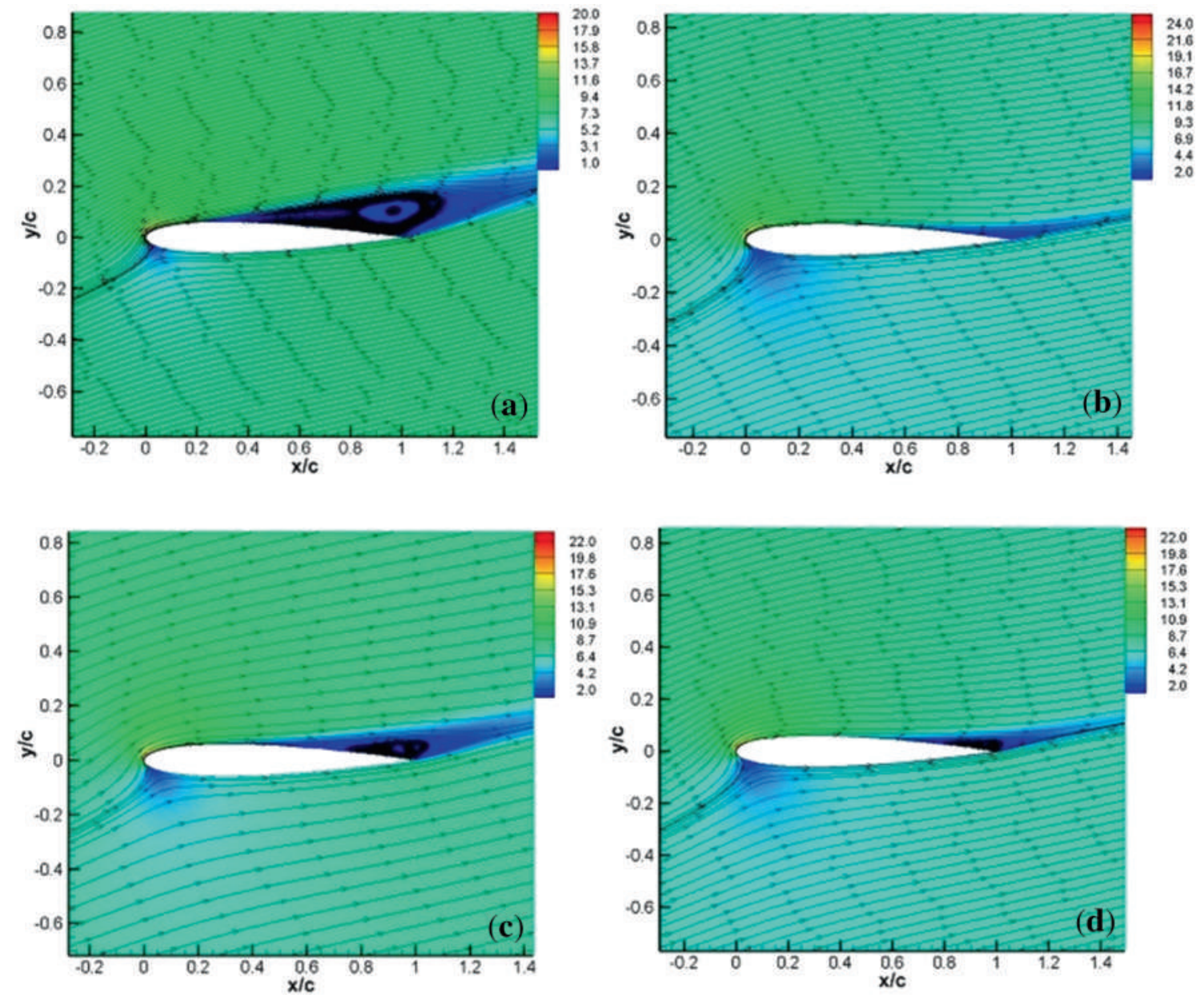

Figure 23. The velocity streamlines colored by velocity magnitude (m/s) contours (a) NACA 0012 airfoil, (b) single suction jet, (c) single blowing jet and (d) simultaneous suction and blowing jets.

flap case which was equal to 73.7. In a single blowing case, the value of lift-to-drag ratio only obtained about 2 times greater than the without flap case. Moreover, the value of $\mathrm{C}_{\mathrm{L}} / \mathrm{C}_{\mathrm{D}}$ had significantly increased by applying a single suction case and simultaneous suction and blowing case. Based on the results, applying a single suction jet and simultaneous suction and blowing jets on the flapped airfoil were more effective than applying these cases to the without flap case. In a single suction case and simultaneous suction and blowing case, the value of the lift-to-drag ratio achieved approximately 10 and 9 times greater than the without control cases over NACA 0012 flapped airfoil, 

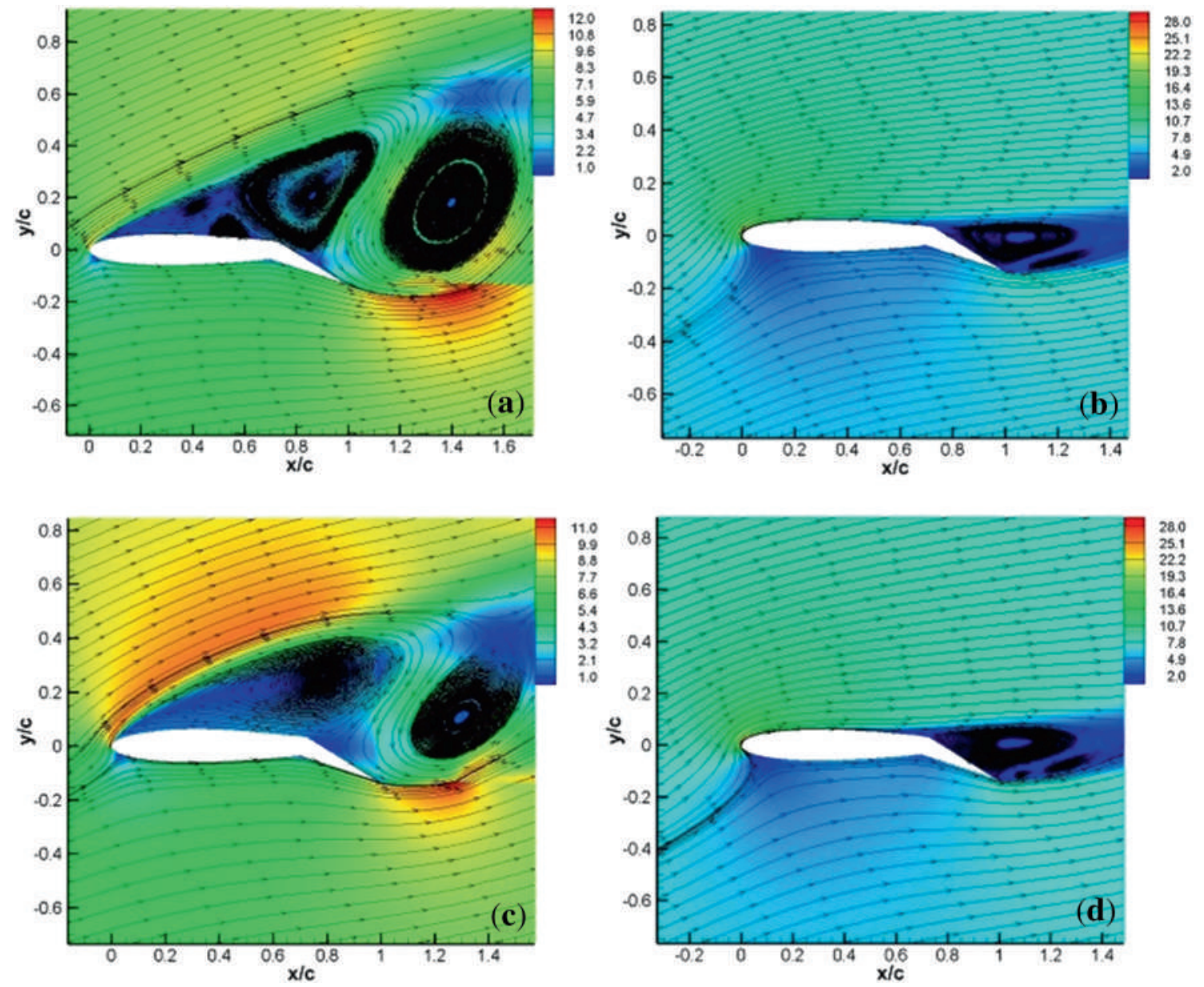

Figure 24. The velocity streamlines colored by velocity magnitude (m/s) contours (a) NACA 0012 flapped airfoil, (b) single suction jet, (c) single blowing jet and (d) simultaneous suction and blowing jets.

respectively. Also, a single blowing case was found to be worse than a single suction case and simultaneous suction and blowing case. The lift-to-drag ratio was increased by only $15 \%$.

\subsection{Velocity streamlines over the airfoil with/ without flap}

Figure 23 illustrates the velocity streamlines colored by velocity magnitude $(\mathrm{m} / \mathrm{s})$ contours of the best-obtained results around the NACA 0012 airfoil at $\alpha=16^{\circ}$. As the boundary layer separates, its displacement thickness increases sharply resulting in an increase in drag, and if severe enough will also result in stall and loss of lift, all of which are undesirable. As it can be seen, all control jets had a positive effect on delaying flow separation. For the without control cases over NACA 0012 airfoil, the separation occurred at 0.2 of the chord length from the airfoil leading edge. Applying a single suction jet had a remarkable effect and completely eliminated the recirculation zone. In this case, the separation occurred at 0.67 of the chord length from the airfoil leading edge. In addition, the separation in simultaneous suction and blowing case and a single blowing case occurred at 0.52 and 0.35 of the chord length from the airfoil leading edge, respectively. The main purpose of using suction is to remove the low-energy boundary layer, while using blowing will energize the boundary layer and change the velocity profile. This will enhance the velocity profile and delay the occurrence of separation over the airfoil [51].

Figure 24 shows the velocity streamlines colored by velocity magnitude $(\mathrm{m} / \mathrm{s})$ contours of the best-obtained results around the NACA 0012 flapped airfoil at $\alpha=16^{\circ}$. Although using flap increased lift coefficient at lower angles of attack, but it made larger vortexes in the trailing edge compared to the without flap case. Using a single blowing jet did not affect significantly on delaying flow separation. Considerable recirculation zone transferred to downstream by applying a single suction jet and simultaneous suction and blowing jets.

Figure 25 demonstrates the velocity streamlines of the present study compared with the flow visualization of experimental results of Jacobs et al [47]. It was observed 

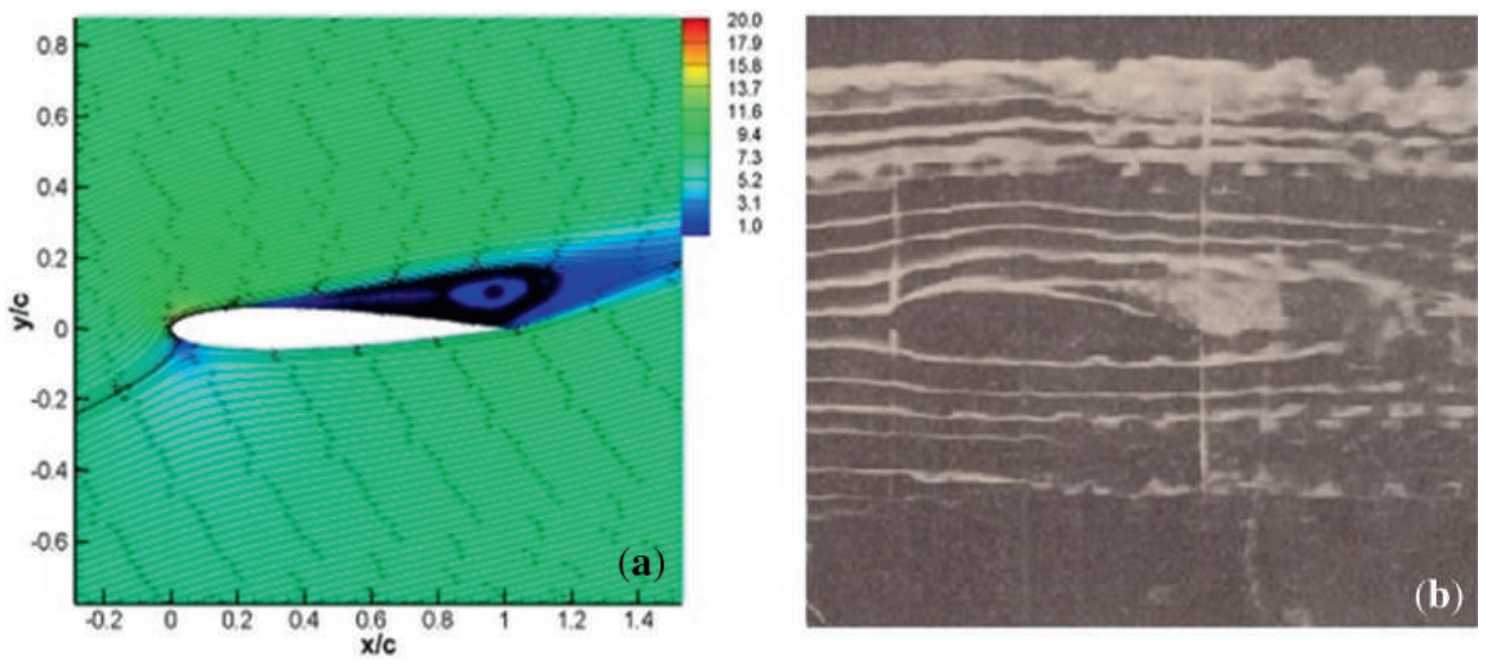

Figure 25. Comparison between the velocity streamlines of (a) the present study and (b) flow visualization of the experimental study of Jacobs et al [47].

that the onset of separation was correctly predicted using CFD simulation. A qualitative good agreement was observed between the CFD simulation of the present study and flow visualization of the experimental study of Jacobs et al [47]. A recirculation zone was captured for both numerical and visualized flow pattern that ensured a good agreement between them.

\section{Conclusion}

A comparative numerical study of flow separation control has been conducted to consider the aerodynamic performance of an airfoil with/without flap with different configurations of flow control jets including single and simultaneous suction and blowing methods. In addition, different parameters including two jet locations $\left(\mathrm{L}_{\mathrm{jet}}\right)$, three suction velocity ratios $\left(\mathrm{R}_{\mathrm{jet}}\right)$, three jet angles $\left(\theta_{\mathrm{jet}}\right)$, and three flap deflections $\left(\delta_{\mathrm{f}}\right)$ were considred to find the most effective case of applying flow control jets for delaying the boundary layer separation. Computation results carried out at a chord Reynolds number of $5 \times 10^{5}$. The turbulence model was SST k- $\omega$ and two-dimensional incompressible URANS equations solved with the finite volume method. Good agreement was obtained between the present results and the previous experimental and numerical results. The computation results indicated that using the flap had a positive effect on the increment of the lift coefficient but it had an unsuitable effect on drag coefficient which caused to decrease the lift-to-drag ratio especially at high flap deflections $\left(\delta_{\mathrm{f}}\right)$. Based on the results, it was observed that higher suction jet angles and suction velocity ratios had the most effect on the aerodynamic performance for the airfoil with/without flap. The lift coefficient enhanced by $41 \%$, and the drag coefficient reduced by $78 \%$, with a suction velocity ratio of 0.15 and a jet angle of $-90^{\circ}$ at $\alpha=16^{\circ}$ compared to the without control cases over NACA 0012 airfoil. Furthermore, by applying a single suction on the flapped airfoil with a deflection of $30^{\circ}$, the lift coefficient increased about $60 \%$ and the drag coefficient decreased by $82 \%$ with $\mathrm{R}_{\text {jet }}=0.15$ and a jet angle of $-90^{\circ}$ at $\alpha=16^{\circ}$. Comparison results demonstrated that applying a single suction jet and simultaneous suction and blowing jets on the flapped airfoil were more effective than applying these cases to the without flap case. The maximum value of $\mathrm{C}_{\mathrm{L}} /$ $C_{D}$ was achieved by a single suction jet for the without flap case which was equal to 73.7. Also, a single suction jet transferred the separation point from 0.2 to 0.67 of the chord length from the leading edge of the without control cases over NACA 0012 airfoil. Considerable recirculation zones transferred to downstream by applying a single suction jet and simultaneous suction and blowing jets on the flapped airfoil.

\section{List of symbols}

$\alpha \quad$ Angle of attack

$\beta \quad$ The angle between the freestream velocity direction and the local jet surface

c Airfoil chord length

$\mathrm{C}_{\mathrm{P}} \quad$ Pressure coefficient

$\mathrm{C}_{\mathrm{L}} \quad$ Lift coefficient

$\mathrm{C}_{\mathrm{D}} \quad$ Drag coefficient

$\varepsilon \quad$ Turbulent dissipation rate

k Turbulent kinetic energy

$\mu \quad$ Viscosity

$\mu_{\mathrm{t}} \quad$ Turbulent viscosity

$\rho \quad$ Density

$\tau \quad$ Shear stress

$\delta_{\mathrm{f}} \quad$ Flap deflection 
P Pressure

Re Reynolds number

$\mathrm{U}_{\infty} \quad$ Free stream velocity

$\mathrm{Y}^{+} \quad$ Dimensionless wall distance

$\delta_{i j} \quad$ Kronecker Delta

$\theta_{\text {jet }} \quad$ Jet angle

$\mathrm{L}_{\text {jet }}$ Jet location

$\mathrm{U}_{\text {jet }}$ Jet velocity

$\mathrm{R}_{\text {jet }} \quad$ Jet velocity ratio

\section{References}

[1] Kim J, Hahn S, Kim J, Lee D K, Choi J, Jeon W P and Choi H 2004 Active control of turbulent flow over a model vehicle for drag reduction. J. Turbul. 5: 1-12

[2] You D and Moin P 2008 Active control of flow separation over an airfoil using synthetic jets. J. Fluid Struct. 24: 1349-1357

[3] Lin J C, Howard F G and Selby G V 1990 Small submerged vortex generators for turbulent flow separation control. $J$. Spacecraft Rockets 27: 503-507

[4] Zhou Y, Hou L and Huang D 2017 The effects of Mach number on the flow separation control of airfoil with a small plate near the leading edge. Comput. Fluids 156: 274-282

[5] Yousefi K, Saleh S R and Zahedi P 2013 Numerical investigation of suction and length of suction jet on aerodynamic characteristics of the NACA 0012 airfoil. Int. J. Mater. Mech. Manuf. 1: 136-142

[6] Fatahian E, Nichkoohi A L and Fatahian H 2019 Numerical study of the effect of suction at a compressible and high Reynolds number flow to control the flow separation over Naca 2415 airfoil. Prog. Comput. Fluid Dyn. 19: 170-179

[7] Huang L, Huang P G, LeBeau R P and Hauser T 2004 Numerical study of blowing and suction control mechanism on NACA0012 airfoil. J. Aircraft 41: 1005-1013

[8] Fatahian H, Salarian H, Nimvari M E and Fatahian E 2018 Numerical study of suction and blowing approaches to control flow over a compressor cascade in turbulent flow regime. Int. J. Automot. Mech. Eng. 15: 1-18

[9] Cattafesta III L N and Sheplak M 2011 Actuators for active flow control. Annu. Rev. Fluid Mech. 43: 247-272

[10] Huang L, Huang G, LeBeau R and Hauser T 2004 Optimization of blowing and suction control on NACA0012 airfoil using genetic algorithm. In: 42nd AIAA Aerospace Sciences Meeting and Exhibit, pp. 225-234

[11] Huang L, Huang G, LeBeau R P and Hauser T 2007 Optimization of airfoil flow control using a genetic algorithm with diversity control. J. Aircraft 44: 1337-1349

[12] LeBeau R, Beliganur N, Hauser T and Schauerhamer D 2007 Applying genetic algorithms to complex computational fluid dynamics simulations. In: 45th AIAA Aerospace Sciences Meeting and Exhibit, pp. 766-775

[13] Shehata H, Zakaria M, Hussein A and Hajj M R 2018 Aerodynamic analysis of flapped airfoil at high angles of attack. In: 2018 AIAA Aerospace Sciences Meeting, pp. $37-749$
[14] Mohammadi M and Taleghani A S 2014 Active flow control by dielectric barrier discharge to increase stall angle of a NACA0012 airfoil. Arab. J. Sci. Eng. 39: 2363-2370

[15] Arunraj R, Logesh K, Balaji V, Ravichandran T and Yuvashree G K 2019 Experimental investigation of lift enhancement by suction-assisted delayed separation of the boundary layer on NACA 0012 airfoil. Int. J. Ambient Energy 40: 243-247

[16] Seifert A, Bachar T, Koss D, Shepshelovich M and Wygnanskil I 1993 Oscillatory blowing: a tool to delay boundary-layer separation. AIAA J. 31: 2052-2060

[17] Seifert A, Darabi A and Wyganski I 1996 Delay of airfoil stall by periodic excitation. J. Aircraft 33: 691-698

[18] Seifert A and Pack L 1999 Oscillatory excitation of unsteady compressible flows over airfoils at flight Reynolds numbers. In: 37th Aerospace Sciences Meeting and Exhibit, pp. $925-936$

[19] Greenblatt D and Wygnanski I J 2000 The control of flow separation by periodic excitation. Prog. Aerosp. Sci. 36: 487-545

[20] James S E, Suryan A, Sebastian J J, Mohan A and Kim H D 2018 Comparative study of boundary layer control around an ordinary airfoil and a high lift airfoil with secondary blowing. Comput. Fluids. 164: 50-63

[21] Critzos C C, Heyson H H and Boswinkle Jr R W 1955 Aerodynamic characteristics of NACA 0012 airfoil section at angles of attack from 0 deg to $180 \mathrm{deg}$. No. NACA-TN-3361. National Aeronautics and Space Administration, Washington DC

[22] Genç M S, Kaynak Ü and Yapici H 2011 Performance of transition model for predicting low $\mathrm{Re}$ aerofoil flows without/with single and simultaneous blowing and suction. Eur. J. Mech. B-Fluid 30: 218-235

[23] Yousefi K, Saleh R and Zahedi P 2014 Numerical study of blowing and suction slot geometry optimization on NACA 0012 airfoil. J. Mech. Sci. Technol. 28: 1297-1310

[24] Boualem K, Yahiaoui T and Azzi A 2017 Numerical investigation of improved aerodynamic performance of a NACA 0015 airfoil using synthetic jet. Int. J. Mech. Aerosp. Ind. Mechatron. Manuf. Eng. 11: 487-491

[25] Lei J, Liu Q and Li T 2019 Suction control of laminar separation bubble over an airfoil at low Reynolds number. Proc. Inst. Mech. Eng. G-J Aerosp. 233: 81-90

[26] Tadjfar M and Asgari E 2018 Active flow control of dynamic stall by means of continuous jet flow at Reynolds number of $1 \times 10^{6}$. J. Fluid Eng. 140: 1-22

[27] Obeid S, Jha R and Ahmadi G 2017 RANS simulations of aerodynamic performance of NACA 0015 flapped airfoil. Fluids 2: 1-15

[28] Hassan A 1999 Predicted aerodynamic characteristics of a NACA 0015 airfoil having a 25\% integral-type trailing edge flap. NACA CR/-1999-209328; NASA Technical Reports Server (NTRS): Hampton, VA, USA, pp. 209-328

[29] Zhang W, Zhang Z, Chen Z and Tang Q 2017 Main characteristics of suction control of flow separation of an airfoil at low Reynolds numbers. Eur. J. Mech. B Fluid 65: 88-97

[30] Ma D, Li G, Yang M and Wang S 2018 Research of the suction flow control on wings at low Reynolds numbers. Proc. Inst. Mech. Eng. G-J Aerosp. 232: 1515-1528 
[31] Ockfen A E and Matveev K I 2009 Aerodynamic characteristics of NACA 4412 airfoil sction with flap. Int. J. Nav. Arch. Ocean 1: 1-12

[32] Menter F R 1994 Two-equation eddy-viscosity turbulence models for engineering applications. AIAA J. 32: 1598-1605

[33] Catalano P and Amato M 2003 An evaluation of RANS turbulence modelling for aerodynamic applications. Aerosp. Sci. Technol. 7: 493-509

[34] Menter F R, Kuntz M and Langtry R 2003 Ten years of industrial experience with the SST turbulence model. Turbul. Heat Mass Transf. 4: 625-632

[35] Cao S, Li Y, Zhang J and Deguchi Y 2019 Lagrangian analysis of mass transport and its influence on the lift enhancement in a flow over the airfoil with a synthetic jet. Aerosp. Sci. Technol. 86: 11-20

[36] Hao W, Ding Q and Li C 2019 Optimal performance of adaptive flap on flow separation control. Comput. Fluids, 179: 437-448

[37] Liang C and Li H 2018 Effects of optimized airfoil on vertical axis wind turbine aerodynamic performance. J. Braz. Soc. Mech. Sci. 40: 88-100

[38] Liu D and Nishino T 2019 Unsteady RANS simulations of strong and weak 3D stall cells on a 2D pitching aerofoil. Fluids 4: 40-52

[39] Wu Z, Cao Y, Nie S and Yang Y 2017 Effects of rain on vertical axis wind turbine performance. J. Wind Eng. Ind. Aerodyn. 170: 128-140

[40] Wu Z and Cao Y 2015 Numerical simulation of flow over an airfoil in heavy rain via a two-way coupled EulerianLagrangian approach. Int. J. Multiphas. Flow 69: 81-92

[41] Versteeg H K and Malalasekera W 2007 An introduction to computational fluid dynamics: the finite volume method, 2nd edn. Pearson education, UK, pp. 273-279

[42] Ge M, Zhang H, Wu Y and Li Y 2019 Effects of leading edge defects on aerodynamic performance of the S809 airfoil. Energy Convers. Manag. 195: 466-479

[43] Monir H E, Tadjfar M and Bakhtian A 2014 Tangential synthetic jets for separation control. J. Fluid Struct. 45: $50-65$
[44] Resendiz Rosas C 2005 Numerical simulation of flow separation control by oscillatory fluid injection. Doctoral dissertation, Texas A \& M University

[45] Yousefi K and Saleh R 2014 The effects of trailing edge blowing on aerodynamic characteristics of the NACA 0012 airfoil and optimization of the blowing slot geometry. $J$. Theor. Appl. Mech. 52: 165-179

[46] Dannenberg R E and Weiberg J A 1952 Section characteristics of a 10.5-percent-thick airfoil with area suction as affected by chordwise distribution of permeability. NASA TN 2847

[47] Jacobs E N and Sherman A 1937 Airfoil section characteristics as affected by variations of the Reynolds number. NACA Report, No. 586-231

[48] Farhadi A, Rad E G and Emdad H 2017 Aerodynamic multiparameter optimization of NACA0012 airfoil using suction/ blowing jet technique. Arab. J. Sci. Eng. 42: 1727-1735

[49] Gregory N and O'reilly C L 1973 Low-speed aerodynamic characteristics of NACA 0012 aerofoil section, including the effects of upper-surface roughness simulating hoar frost. London: HM Stationery Office

[50] Schlichting H and Gersten K 2000 Boundary-layer control (suction/blowing). In: Boundary-Layer Theory. Berlin, Heidelberg: Springer, pp. 291-320

[51] Mazaheri K, Nejati A and Kiani K C 2017 The application of suction and blowing in performance improvement of transonic airfoils with shock control bump. Sci. IRAN Trans. B 24: 274-283

[52] Chen C, Seele R and Wygnanski I 2012 Separation and circulation control on an elliptical airfoil by steady blowing. AIAA J. 50: 2235-2247

[53] Chen C, Seele R and Wygnanski I 2013 Flow control on a thick airfoil using suction compared to blowing. AIAA J. 51: 1462-1472

[54] Williamson G 2012 Experimental wind tunnel study of airfoils with large flap deflections at low Reynolds numbers. Master's Thesis, Aerospace Engineering, The University of Illinois at Urbana-Champaign, Champaign, IL, USA, pp. 14-60 